\title{
Observations of $\mathrm{SO}_{2}$ and $\mathrm{NO}_{2}$ by mobile DOAS in the Guangzhou eastern area during the Asian Games 2010
}

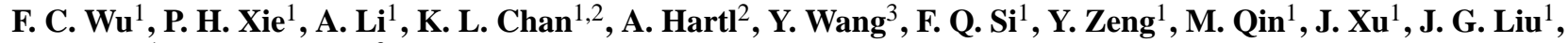 \\ W. Q. Liu ${ }^{1}$, and M. Wenig ${ }^{3}$ \\ ${ }^{1}$ Key Laboratory of Environmental Optical and Technology, Anhui Institute of Optics and Fine Mechanics, Chinese Academy \\ of Sciences, Hefei, China \\ ${ }^{2}$ School of Energy and Environment, City University of Hong Kong, Hong Kong, China \\ ${ }^{3}$ Meteorological Institute, Ludwig-Maximilians-Universität München, Munich, Germany
}

Correspondence to: P. H. Xie (phxie@aiofm.ac.cn)

Received: 7 October 2012 - Published in Atmos. Meas. Tech. Discuss.: 7 January 2013

Revised: 14 July 2013 - Accepted: 26 July 2013 - Published: 4 September 2013

\begin{abstract}
Mobile passive differential optical absorption spectroscopy measurements of $\mathrm{SO}_{2}$ and $\mathrm{NO}_{2}$ were performed in the Guangzhou eastern area (GEA) during the Guangzhou Asian Games 2010 from November 2010 to December 2010. The observations were carried out between 10:00 to 13:00 (local time, i.e., during daylight). Spatial and temporal distributions of $\mathrm{SO}_{2}$ and $\mathrm{NO}_{2}$ in this area were obtained and emission sources were determined using wind field data. The $\mathrm{NO}_{2}$ vertical column densities were found to agree with Ozone Monitoring Instrument values. The correlation coefficient (referred to as $R^{2}$ ) was 0.88 after cloud filtering within a specific ground pixel. During the Guangzhou Asian Games and Asian Paralympics (Para) Games, the $\mathrm{SO}_{2}$ and $\mathrm{NO}_{\mathrm{x}}$ emissions in the area were quantified using averaged wind speed and wind direction. For times outside the games the average $\mathrm{SO}_{2}$ emission was estimated to be $9.50 \pm 0.90$ tons per hour and the average $\mathrm{NO}_{\mathrm{x}}$ emission was estimated to be $5.87 \pm 3.46$ tons per hour. During the phases of the Asian and Asian Para Games, the $\mathrm{SO}_{2}$ and $\mathrm{NO}_{\mathrm{x}}$ emissions were reduced by $53.50 \%$ and $43.50 \%$, respectively, compared to the usual condition. We also investigated the influence of GEA on Guangzhou University Town, the main venue located northwest of the GEA, and found that $\mathrm{SO}_{2}$ concentrations here were about tripled by emissions from the GEA.
\end{abstract}

\section{Introduction}

$\mathrm{NO}_{2}$ is an important trace gas in the atmosphere because it readily undergoes photochemical reactions with other atmospheric constituents. In the atmosphere, NO reacts rapidly with ozone to $\mathrm{NO}_{2}$, which during the day photolyzes back to NO. The tropospheric production of ozone is thus greatly influenced by $\mathrm{NO}_{\mathrm{x}}$ (sum of $\mathrm{NO}$ and $\mathrm{NO}_{2}$ ). $\mathrm{NO}_{2}$ also has an important influence on human health. For example, longterm exposure to $\mathrm{NO}_{2}$ increases the symptoms of bronchitis in asthmatic children (WHO, 2006). The major sources of anthropogenic emissions of $\mathrm{NO}_{2}$ are combustion processes such as heating, power generation, and engines in vehicles and ships (Finlayson-Pitts et al., 1999). $\mathrm{SO}_{2}$ is a colorless gas that adversely affects the respiratory system, especially the lungs. The main anthropogenic source of $\mathrm{SO}_{2}$ is the burning of sulfur-containing fossil fuels for domestic heating and power generation. $\mathrm{SO}_{2}$ and $\mathrm{NO}_{2}$ tend to form sulfuric and nitric acids, respectively, which in the form of acid rain, are one of the causes of deforestation (WHO, 2006).

Population growth, industrial development, and heavy traffic lead to higher energy consumption and, therefore, an increase in the emission of pollutants such as $\mathrm{SO}_{2}, \mathrm{NO}_{2}$, and volatile organic compounds (VOCs) into the atmosphere, if no measures are taken to counteract this development. In recent years, China has experienced a significant increase in atmospheric pollutant concentrations because of rapid industrial development, which has an important impact on ecosystems and human health. The Pearl River delta (PRD) in the 
south of China is one of the three major economic areas (the other two are the Yangtze River delta and the BeijingTianjin-Hebei economic region). It includes many populated and strongly industrialized cities such as Guangzhou and Shenzhen, and has experienced an extremely fast economic development (Zhang et al., 2008a, b; Wang et al., 2008). PRD has a total land area of $42794 \mathrm{~km}^{2}$ and a population of over 38 million (Cao et al., 2004). As a result, emissions of $\mathrm{SO}_{2}$, $\mathrm{NO}_{2}$, and other pollutants have also largely increased in this area (Zhang et al., 2007).

The 16th Asian Games were held in the city of Guangzhou from November 2010 to December 2010. The pollutant sources were identified in order to alleviate air pollution for this occasion. In addition, strategies including emission control for factories, vehicle limitation, and so forth were employed by the Guangzhou government to reduce the air pollution problem during the Asian Games. The Guangzhou eastern area (GEA) (Fig. 1) was considered the most seriously affected region of the city because of the many pollutant sources present, such as the Guangdong Yuehua Power Plant (the largest power plant in Guangzhou according to the Guangzhou Environmental Center), the Guangzhou Hengyun thermal power company, and the Guangzhou Zhujiang steel company, where air pollutants such as $\mathrm{SO}_{2}, \mathrm{NO}_{2}$, VOCs, and fine particulates are emitted. Regional studies investigated that area sources have a very strong influence on air quality through the regional transport of air pollutants, possibly causing severe pollution events to the area and its neighbors (Melamed et al., 2009; Takashima et al., 2011). The temporal and spatial scale of transport can range from a few days to several weeks and from a few kilometers to hundreds of kilometers. Therefore, understanding the spatial and temporal distribution as well as the emission sources of air pollutants in GEA was important for environmental management during the Guangzhou Asian Games. Air pollutants were routinely monitored by the local environmental protection agency using a network of ground-level monitors. However, data from this network were insufficient for spatial distribution and transportation processes as well as emission sourcing.

Previously, regional studies in the PRD combined aircraft measurements and modeling studies to examine spatial and vertical distributions of $\mathrm{O}_{3}, \mathrm{SO}_{2}, \mathrm{NO}_{\mathrm{x}}, \mathrm{PM}_{10}$, and $\mathrm{PM}_{2.5}$ (Wang et al., 2008); or used a bottom-up approach to estimate emissions of $\mathrm{NO}_{\mathrm{x}}, \mathrm{SO}_{2}, \mathrm{CO}$, VOCs, and fine particulates (Zheng et al., 2009; He et al., 2011). These studies focused on the larger area of the PRD but did not consider smaller-scale distributions of air pollutants or area sources like the GEA. In this study, passive differential optical absorption spectroscopy (DOAS) on a mobile platform (referred to as mobile DOAS in the following) was used to detect spatial and temporal distributions and emissions of $\mathrm{SO}_{2}$ and $\mathrm{NO}_{2}$ related to the GEA. This technique was first used to measure volcanic emissions (Edner et al., 1994; Galle et al., 2003) and subsequently applied to determine the emis- sion of point sources (e.g., power plants, oil refineries, etc.) and area sources (e.g., cities and industrial areas). Johansson et al. $(2008,2009)$ and Rivera et al. (2009) examined the outflow of $\mathrm{SO}_{2}, \mathrm{NO}_{2}$, and $\mathrm{HCHO}$ in Mexico, Beijing and the Tula industrial area in the city of Mexico. $\mathrm{NO}_{\mathrm{x}}$ emissions in Mannheim and Ludwigshafen, Germany, using mobile MAX-DOAS (multi-axis differential optical absorption spectroscopy) were investigated by Ibrahim et al. (2010). The same method was used by Shaiganfar et al. (2011) to quantify emissions in Delhi. In China, several measurements based on mobile DOAS were also carried out (Li et al., 2005, 2007a; Wu et al., 2011). However, in previous field measurements that used a zenith viewing DOAS instrument on a mobile platform, emissions were estimated by first taking a "cleanair" spectrum at some point along the measurement path and using it as a reference spectrum to obtain differential vertical columns relative to this "clean-air" measurement ( $\mathrm{Li}$ et al., 2005, 2007a; Wu et al., 2011). For the field campaign reported in the present study, concurrent measurements of a MAX-DOAS instrument at a fixed location were used to obtain estimates of absolute vertical columns for $\mathrm{NO}_{2}$ and $\mathrm{SO}_{2}$, making the analysis of data from the mobile measurement relatively simple (see detailed description in Sect. 2.4.1).

In this paper, we present mobile DOAS measurements carried out from 9 November to 26 December (each day from 10:00 to 13:00 local time) during the Asian Games 2010 in Guangzhou, South China. We derived vertical columns of $\mathrm{SO}_{2}$ and $\mathrm{NO}_{2}$ along a closed path around the GEA in combination with data from stationary MAX-DOAS to estimate emissions from this area. We study the variation of these pollutants for different wind fields and emission periods during the games, thereby identifying individual sources. Furthermore, we compare $\mathrm{NO}_{2}$ vertical columns from our mobile measurements to those from Ozone Monitoring Instrument (OMI). Finally, the influence of GEA emissions on the venue of the games at Guangzhou University Town is explored.

The paper is organized as follows: in Sect. 2, the measurements in GEA, our measurement instrument, and principle are introduced. In Sect. 3, our results and discussions, including the distributions of $\mathrm{SO}_{2}$ and $\mathrm{NO}_{2}$ around GEA, the comparison with $\mathrm{OMI} \mathrm{NO}$, and emissions of $\mathrm{SO}_{2}$ and $\mathrm{NO}_{\mathrm{x}}$ from GEA with their influence on the downwind region are all presented. In Sect. 4, the results of our study are summarized.

\section{Experiment and data analysis}

\subsection{Description of the measurements in GEA}

GEA is located southeast of Guangzhou City and west of Dongguan City (Fig. 1). The measurement route shown in Fig. 1 starts from the Huangpu East Road clockwise to Huangpu Bridge surrounding GEA. The total path is about $140 \mathrm{~km}$ and covers an area of about $1000 \mathrm{~km}^{2}$, and takes 

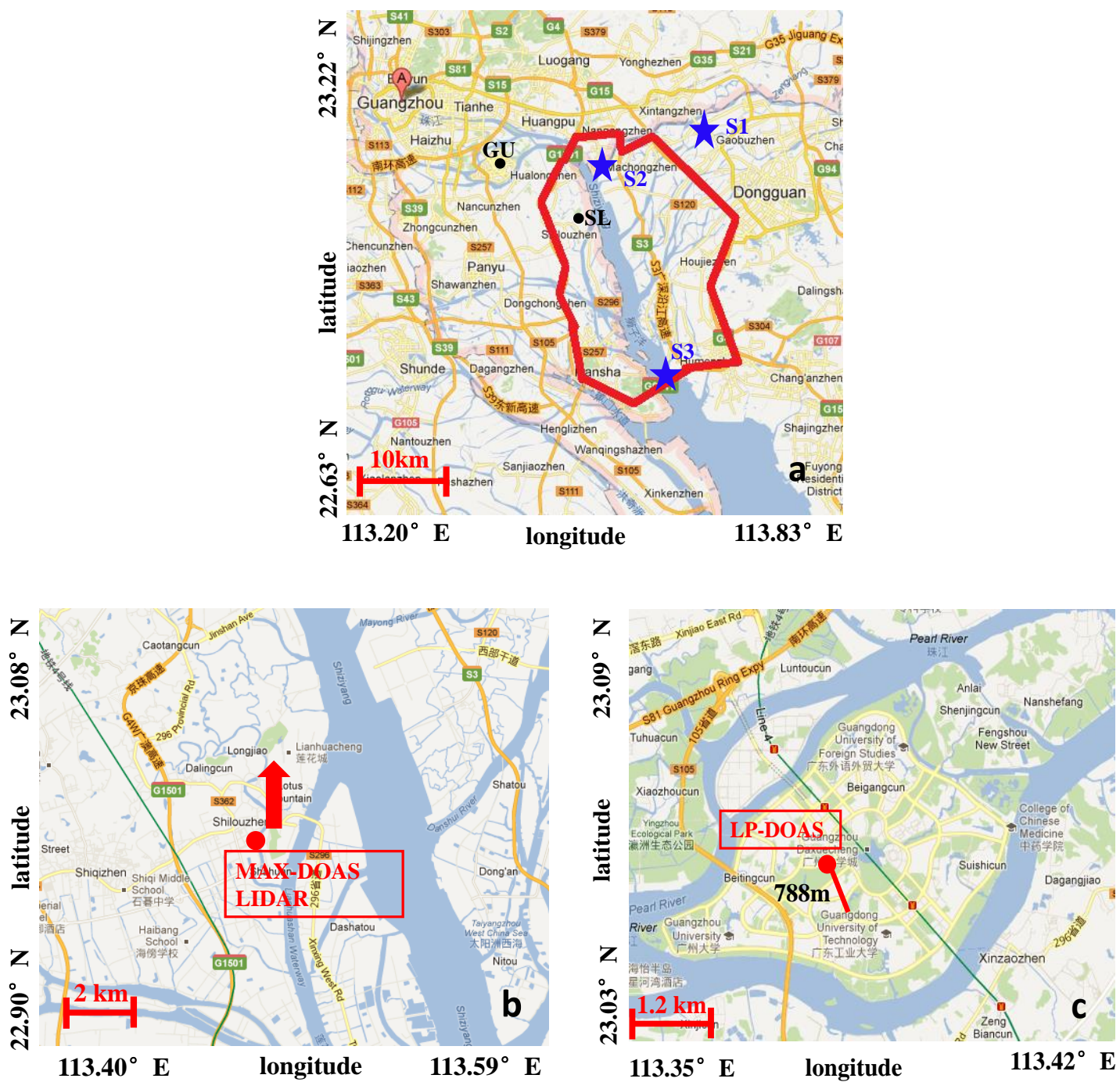

Fig. 1. Location of the Guangzhou eastern area (GEA). (a) The mobile DOAS measurement path encircling this area is indicated by the closed red line. SL: Shilou in Guangzhou City, location of MAX-DOAS and lidar; GU: Guangzhou University Town, location of LP-DOAS. S1, S2, and S3 represent three different pollutant sources. The maps of SL and GU are shown in (b) and (c), respectively. The arrow indicates the viewing direction (north) of the MAX-DOAS in (b). The light-path of LP-DOAS is about $788 \mathrm{~m}$ in (c).

approximately $2.5 \mathrm{~h}$ to complete. Our measurements took place for seven weeks, from 9 November to 26 December 2010, starting every odd day at $10 \mathrm{a} . \mathrm{m}$. and encircled the GEA once during each day of measurement. The Guangzhou Municipal Government attempted to control traffic-induced air pollution for the Asian and Asian Para Games by limiting the number of vehicles in the city area during these events. Vehicles with odd number plates were only allowed to drive on odd days from 1 November to 29 November and from 5 to 21 December 2010, whereas vehicles with even number plates were allowed only on even days. Our van has an odd number plate; therefore, we had a total of 25 days of measurements. During the entire measurement period, the temperature varied from 22 to $28^{\circ} \mathrm{C}$, and the wind blew predom- inantly from the north/northeast (see Sect. 3.1.1 for further details).

\subsection{Description of the instrument}

Our mobile DOAS instrument records sunlight scattered into the telescope pointing to the zenith. The mobile DOAS system was developed at the Anhui Institute of Optics and Fine Mechanics (AIOFM). The components of our AIOFM mobile DOAS instrument are the telescope, a UV/VIS detector spectrometer unit, a computer, and a global positioning system (GPS). The lens telescope with $80 \mathrm{~mm}$ diameter and $170 \mathrm{~mm}$ focal length is used to collect scattered sunlight. Light collected by the telescope is transmitted to the spectrometer (Ocean Optics HR2000) through a $3 \mathrm{~m}$ length 
optical fiber with diameter of $400 \mu \mathrm{m}$. The field of view of the telescope is about $0.1^{\circ}$. The spectrometer has a spectral resolution of about $0.6 \mathrm{~nm}$ (FWHM) and a spectral range of $290 \mathrm{~nm}$ to $420 \mathrm{~nm}$. It is placed in a small refrigerator to stabilize the temperature at $+25 \pm 0.5^{\circ} \mathrm{C}$. The GPS tracks the coordinates of the measurement route and provides the car speed and acquisition time for each spectrum. A miniature weather station is used to record meteorological data such as wind speed, wind direction, temperature, humidity, and pressure along the route at street level. The telescope, GPS and weather station are mounted on top of the measurement van. The entire system is automatically controlled by our AIOFM mobile DOAS software and is equipped with a DC (direct current) $+12 \mathrm{~V}$ battery. The $+12 \mathrm{~V}$ direct current is converted to alternating current (AC) by a power converter to power the entire system ( $\mathrm{Li}$ et al., 2005). The detection limits of $\mathrm{SO}_{2}$ and $\mathrm{NO}_{2}$ column densities for the instrument are about $\sim 3-5 \times 10^{15}$ molecules $\mathrm{cm}^{-2}$ (the "molecules $\mathrm{cm}^{-2}$ ", is abbreviated to "molec $\mathrm{cm}^{-2}$ " and the "molecules $\mathrm{cm}^{-3}$ " is abbreviated to "molec $\mathrm{cm}^{-3}$ " in the following).

The long-path DOAS (LP-DOAS) instrument used to explore the influence of GEA on the downwind region (see Sect. 3.4) uses a xenon lamp as light source and a UV/VIS spectrometer (QE65000, Ocean Optics). The detailed setup of the long-path DOAS instrument has been provided by Qin et al. (2006). The instrument is mounted on the third floor (about $15 \mathrm{~m}$ above ground) of one of the office buildings at Guangzhou University Town (Fig. 1), southeast of Guangzhou City, about $20 \mathrm{~km}$ away from GEA. The retro reflector is installed on the roof of a teaching building, southeast of the office building. The total optical path length of LP-DOAS is about $788 \mathrm{~m}$ pointing to the southeast (Fig. 1c). The wavelength coverage of this instrument, ranging from $260 \mathrm{~nm}$ to $369 \mathrm{~nm}$, allows monitoring of $\mathrm{SO}_{2}, \mathrm{HCHO}, \mathrm{NO}_{2}$, and $\mathrm{O}_{3}$ among others. During this campaign, the instrument is mainly used to monitor $\mathrm{SO}_{2}, \mathrm{NO}_{2}$, and $\mathrm{O}_{3}$.

In this study, the MAX-DOAS instrument is used to obtain the vertical columns for $\mathrm{NO}_{2}$ and $\mathrm{SO}_{2}$. This system is also from the AIOFM, with parts such as a stepper motor used to rotate a telescope, a miniature spectrometer (Ocean Optics HR2000) with a spectral resolution of $0.6 \mathrm{~nm}$. Scattered sunlight is collected and focused by the telescope and is led into the spectrometer unit through $3 \mathrm{~m}$ optical fiber. The spectrometer unit is placed in a small refrigerator to stabilize the temperature at $+25 \pm 0.5^{\circ} \mathrm{C}$. The MAX-DOAS telescope is equipped with a stepper motor, therefore allowing for pointing at different elevation viewing angles. During our measurements, scattered sunlight was collected sequentially at $5,10,20,30$, and 90 degree elevation viewing angles. The azimuth viewing direction of the MAX-DOAS is north (Fig. 1b). The detailed description of our MAX-DOAS system is given in Li et al. (2007b). Furthermore, lidar observations (Fig. 1) are carried out by AIOFM. For the vertical columns calculations based on the MAX-DOAS, the height of the boundary layer and aerosol extinction coefficients are deduced from the lidar (Sect. 2.4.1). Light source of the lidar is a pulsed Nd:YAG laser with a repetition rate of $20 \mathrm{~Hz}$ and $6 \mathrm{~ns}$ of pulse duration. It is operating at wavelengths of 532 and $355 \mathrm{~nm}$. A Cassegrainian telescope is designed to receive backscattered light. The detailed descriptions of the lidar system can be found in Chen et al. (2011).

\subsection{Description of OMI}

The Ozone Monitoring Instrument (Levelt et al., 2006) onboard the NASA Earth Observing System (EOS)-Aura satellite was launched on 15 June 2004. It is capable of monitoring global atmospheric $\mathrm{NO}_{2}$ via observation of backscattered sunlight in the wavelength range of $270 \mathrm{~nm}$ to $500 \mathrm{~nm}$. The crossing time for OMI is 13:45 (local time) on the ascending node. Compared with $\mathrm{NO}_{2}$ satellite observations from GOME, GOME-2, and SCHIAMACHY, OMI can provide a data set with higher spatial (up to $13 \mathrm{~km} \times 24 \mathrm{~km}$ ) and temporal resolution (daily global coverage). The OMI retrieval of $\mathrm{NO}_{2}$ vertical columns is based on the DOAS method and consists of three steps: determination of slant column densities, conversion to vertical column densities (VCDs) using the so-called air mass factor (AMF), and estimation of the stratospheric contribution. The detailed description of this retrieval process can be found in Bucsela et al. (2006).

Ground-based measurements cover a limited spatial area, where vertical column densities may not completely represent the whole spatial extent of the satellite ground pixel (Louisa et al., 2008). Airborne measurements (Dix et al., 2009; Heue et al., 2011; Sluis et al., 2010) are costly and usually cannot be carried out on a regular basis. Mobile DOAS observations, on the one hand, can provide more data points within a given satellite ground pixel and be used to detect variability and gradients (Wagner et al., 2010). Furthermore, they can easily be conducted regularly. In the current study, the OMI tropospheric $\mathrm{NO}_{2}$ data product of NASA is used (Bucsela et al., 2006). To achieve a better comparison between $\mathrm{OMI} \mathrm{NO}_{2}$ and mobile DOAS data, the OMI tropospheric $\mathrm{NO}_{2} \mathrm{VCDs}$ are gridded onto a $0.1^{\circ} \times 0.1^{\circ}$ grid (Wenig et al., 2008; Chan et al., 2012).

\subsection{Principle of mobile DOAS}

\subsubsection{Retrieval of vertical columns for tropospheric trace gases}

The DOAS technique has been employed in numerous applications that use artificial light sources or sunlight with instruments mounted on various fixed or mobile platforms (see Platt and Stutz, 2008, for a comprehensive overview). The DOAS evaluation procedure is described in this section in relation to our mobile observation of sunlight intensities in a zenith viewing direction, and the retrieval of tropospheric $\mathrm{SO}_{2}$ and $\mathrm{NO}_{2}$ from these intensity spectra. Details of the DOAS analysis are presented in Platt and Stutz (2008). 

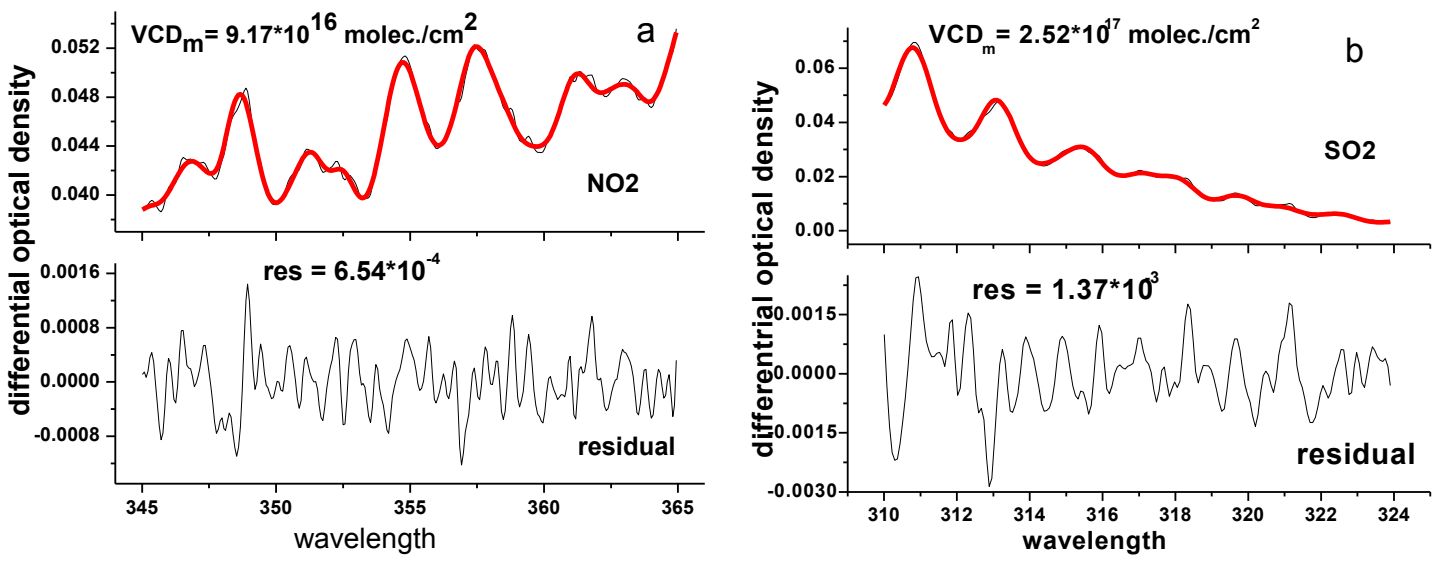

Fig. 2. Example fit for (a) $\mathrm{NO}_{2}$ recorded at 10:42 (LT) on 27 November 2010 and (b) $\mathrm{SO}_{2}$ at 10:35 (LT) on 29 November 2010 by our mobile DOAS instrument. Black lines denote the differential optical densities (DODs) of processed measurement spectra. Red lines show the result of the fit. The number given by $\mathrm{VCD}_{m}$ is the differential VCD with respect to the Frauenhofer reference spectrum as described in Sect. 2.4.1.

The spectral evaluation applied to each recorded spectrum while the van moves along the measurement route starts with dark current and offset corrections, followed by the division with a Frauenhofer reference spectrum. Subsequently, a high-pass filter is applied to the logarithm of this ratio to separate the broad and narrow band spectral structures. Differential slant column densities (DSCD, the difference between the slant column density of a measurement spectra and the reference; slant column density, SCD, defined as the concentration integrated along the light path), are then obtained by fitting narrow band spectral absorption cross sections to the processed measurement spectra. Figure 2 illustrates such a DOAS fit for $\mathrm{NO}_{2}$ and $\mathrm{SO}_{2}$ using the WinDOAS software package (Van Roozendael et al., 2001) for mobile DOAS measurement.

During our retrieval process, a spectrum is first selected arbitrarily on the upwind path as the reference spectrum to obtain the concentration distribution trends along the route. The minimum concentration of $\mathrm{SO}_{2}$ and $\mathrm{NO}_{2}$ along each driving route is then chosen as the Frauenhofer spectra to re-retrieve the measurement spectra. The spectrum with the lowest measurement value for each day is then chosen as the Frauenhofer reference to minimize the effect of potential instrumental changes on different days.

The wavelength range of $310 \mathrm{~nm}$ to $324 \mathrm{~nm}$ with three strong absorption peaks is selected for the $\mathrm{SO}_{2}$ fit. Absorption cross sections of $\mathrm{SO}_{2}, \mathrm{NO}_{2}, \mathrm{HCHO}$ and $\mathrm{O}_{3}$ at $293 \mathrm{~K}$ are taken from Bogumil et al. (2003). Apart from the Frauenhofer reference spectrum, a Ring spectrum is also included in the fit as described in Hönninger et al. (2004). All absorption cross sections are convoluted with the instrument's slit function to adapt to the instrument resolution during the fit process. The emission peak from mercury lamp at $334 \mathrm{~nm}$ is recorded to yield instrument's slit function. The synthetic Ring spectrum is generated from the measured Frauenhofer reference spectrum using the DOASIS software
(Kraus, 2006). For the analysis of $\mathrm{NO}_{2}$, the spectral window of $345 \mathrm{~nm}$ to $365 \mathrm{~nm}$ is selected, and the cross sections of $\mathrm{O}_{4}$ at $298 \mathrm{~K}$ (Greenblatt et al., 1990) and HONO at $298 \mathrm{~K}$ (Stutz et al, 2000) are also included, except for $\mathrm{NO}_{2}, \mathrm{HCHO}$, $\mathrm{O}_{3}$ at $293 \mathrm{~K}$ (Bogumil et al., 2003) and Ring spectrum. The wavelength calibration is performed using a highly resolved solar spectrum (Kurucz et al., 1984) convoluted by the instrument's slit function. An example for such a spectral fitting is shown in Fig. 2, where the fit residual of $\mathrm{NO}_{2}$ (Fig. 2a) and $\mathrm{SO}_{2}$ (Fig. 2b) are $6.54 \times 10^{-4}$ and $1.37 \times 10^{-3}$, respectively, due to the unknown structures and system noise. The fit uncertainties of retrieved values from these two spectra for $\mathrm{NO}_{2}$ and $\mathrm{SO}_{2}$ are about 1.80 and $2.30 \%$, respectively. For all measured spectra the fit uncertainties are less than $15 \%$ for $\mathrm{NO}_{2}$ and $20 \%$ for $\mathrm{SO}_{2}$.

The procedure described so far yields differential slant column densities relative to the reference spectrum. The assumption by Johansson et al. (2008) and Rivera et al. (2009) that around noon the slant column densities for the zenith viewing direction approximate those of the vertical columns is now adopted. The tropospheric vertical columns obtained from the MAX-DOAS observation at the time the mobile DOAS passes its location (Fig. 1) is used in order to eliminate the $\mathrm{NO}_{2}$ and $\mathrm{SO}_{2} \mathrm{VCD}$ in the reference. However, this method is based on the assumption that no strong spatial variations exist within the distance represented by the MAXDOAS measurement (typically several kilometers). The variability of the mobile DOAS VCDs in the form of standard deviation of its values along such a typical distance is shown in Fig. $3 \mathrm{a}$ and $\mathrm{b}$ for $\mathrm{SO}_{2}$ and $\mathrm{NO}_{2}$, respectively. The mobile DOAS VCDs are averaged for about twenty values from twenty spectra in Fig. 3a and b. Since the integration time of an individual spectrum is $10 \mathrm{~s}$ and the average van speed is $70 \mathrm{~km} \mathrm{~h}^{-1}$, this means the van moves about $4 \mathrm{~km}$ in the time these twenty spectra are taken. In terms of these standard deviations, for most days no significant variations can be found. 

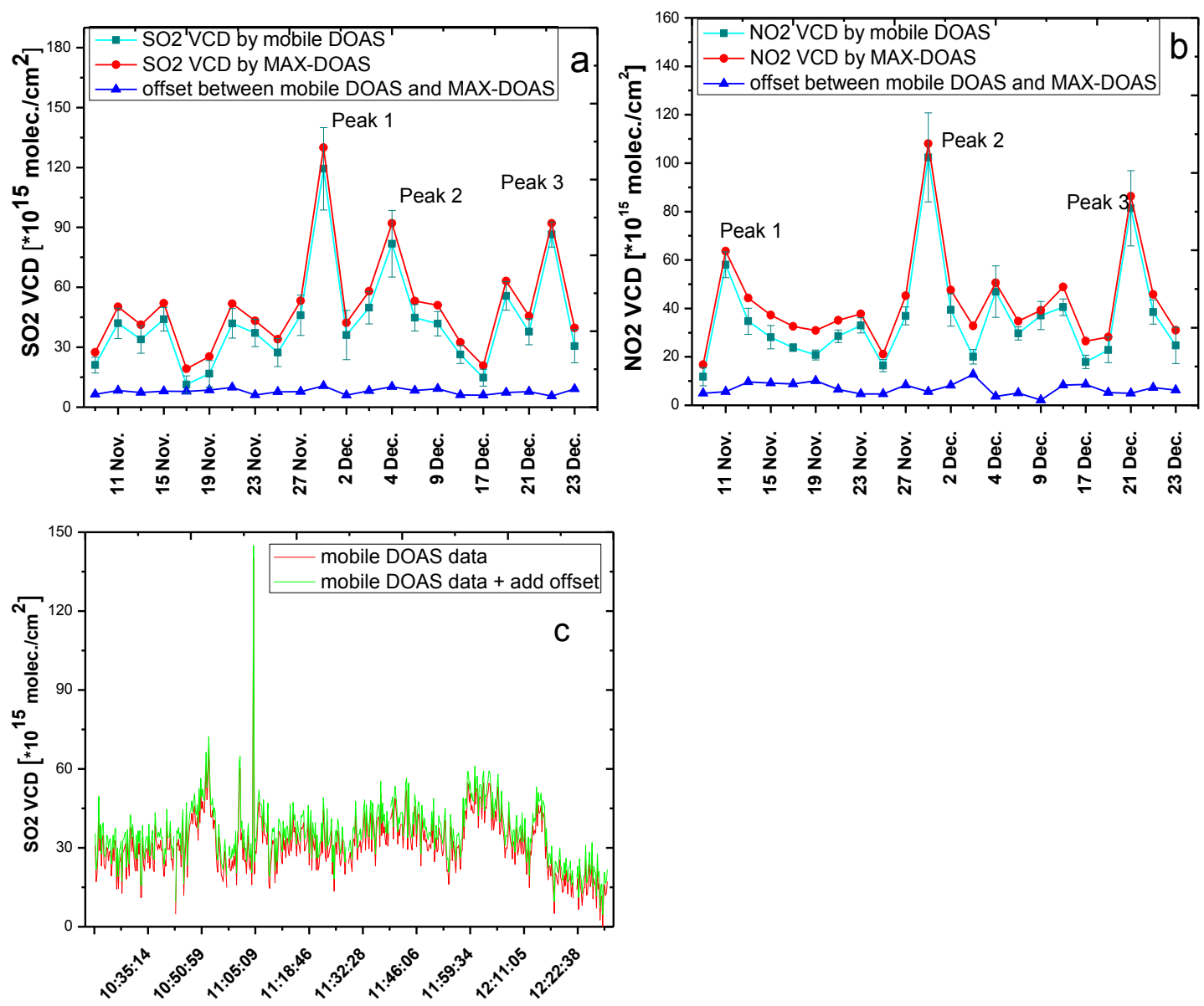

Fig. 3. Offset between MAX-DOAS and mobile DOAS values defined as the difference between these values for the measurement period for $\mathrm{SO}_{2}$ (a) and $\mathrm{NO}_{2}$ (b). The mobile DOAS value represents the average over about twenty spectra data acquired when the mobile DOAS passed the MAX-DOAS location. The MAX-DOAS value is the VCD acquired at the time of the passing by. (c) shows the example for $\mathrm{SO}_{2}$ on 25 November 2010. Red line: original value from mobile DOAS; green line: result after adding the offset. Error bars indicate the standard deviation for the mobile DOAS as described in the text.

Exceptional large variations occur for $\mathrm{SO}_{2}$ on 29 November, and 2 and 4 December, and for $\mathrm{NO}_{2}$ on 29 November, and 4 and 21 December. These maybe related to the variations of the emission sources themselves. In general, however, the above assumption of generally small spatial variations appears reasonable to us.

The difference between the MAX-DOAS VCD and the mobile DOAS differential VCD is considered as the "cleanair" background (this difference is called "offset"). The mobile DOAS differential VCDs are then converted into absolute columns by adding this "offset" to all values along the path.

The retrieval of vertical columns from the MAX-DOAS observations is described by Xu et al. (2010). Differential slant column densities are converted into tropospheric VCDs using tropospheric differential air mass factors (DAMFs) ac- cording to the following formula:

$\mathrm{VCD}_{\text {trop }}=\frac{\mathrm{DSCDs}}{\mathrm{DAMF}}$.

The radiative transfer model SCIATRAN (Rozanov et al., 2002) is used to calculate DAMFs under the assumption that aerosol and trace gas profiles are given by constant values below the boundary layer height and exponential profiles above. The height of the boundary layer was on average about $1.5 \mathrm{~km}$ during our measurements from the lidar observations. For the radiative transfer calculations, aerosol extinction coefficients within the layer are taken from the lidar, while the $\mathrm{NO}_{2}$ and $\mathrm{SO}_{2}$ mixing ratios are obtained from the long-path DOAS measurements. Aerosol and trace gas profiles above the boundary layer are taken from the LOWTRAN database (Kneizys et al., 1988) and the US standard atmosphere (US Government Printing Office, 1976), respectively. The fact that the LP-DOAS measurements take place at a location different from the one of the 
MAX-DOAS is a potential source of error. We estimated the effect on our retrieval to be less than $5 \%$ by varying the setting of $\mathrm{NO}_{2}$ and $\mathrm{SO}_{2}$ loading $\left(2.5 \times 10^{11}\right.$ molec $\mathrm{cm}^{-3}$, $6.25 \times 10^{11} \mathrm{molec} \mathrm{cm}^{-3}$ and $1.25 \times 10^{12} \mathrm{molec} \mathrm{cm}^{-3}$ ) within the boundary layer. Another uncertainty lies in the AOD (Aerosol Optical Depth, AOD) obtained from the lidar boundary layer height and extinction coefficients. A sensitivity study for different AODs (0.3, 0.5, 0.8 and 1.1), fixed boundary layer height of $1.5 \mathrm{~km}$ and constant $\mathrm{NO}_{2}$ and $\mathrm{SO}_{2}$ concentrations of $1 \times 10^{12}$ molec cm${ }^{-3}$ shows a resulting change for the $\mathrm{NO}_{2}$ and $\mathrm{SO}_{2} \mathrm{AMFs}$ at $20^{\circ}$ elevation of less than $10 \%$.

\subsubsection{Emission calculation}

The mobile DOAS measurement allows emission from pollutant sources to be further quantified for known wind direction, wind speed, and car speed. The total $\mathrm{SO}_{2}$ and $\mathrm{NO}_{2}$ emissions from a source are determined using the following Eq. (2) (Johansson et al., 2009; Ibrahim et al., 2010):

Flux $_{\text {gas }}=\sum \mathrm{VCD}_{\text {gas }} \cdot V_{\mathrm{m}} \cdot V_{\mathrm{w}_{\perp}} \cdot \Delta t$,

where $\mathrm{VCD}_{\text {gas }}$ is the vertical column density, $V_{\mathrm{m}}$ is the car speed, $V_{\mathrm{w}_{\perp}}$ is the component of wind speed perpendicular to the driving direction, and $\Delta t$ is the time for acquiring one spectrum (i.e., integration time, about $9 \mathrm{~s}$ in this study). In this equation, the sum refers to all the measurement spectra along the path.

Assuming additional factors for the partitioning between $\mathrm{NO}$ and $\mathrm{NO}_{2}$ and the finite $\mathrm{NO}_{\mathrm{x}}$ lifetime, mobile DOAS measurements allow furthermore determining the total $\mathrm{NO}_{\mathrm{x}}$ $\left(=\mathrm{NO}+\mathrm{NO}_{2}\right)$ emission (Ibrahim et al., 2010; Shaiganfar et al., 2011):

$F_{\mathrm{NO}_{\mathrm{x}}}=R \cdot c_{\tau} \cdot$ Flux $_{\mathrm{NO}_{2}}$.

Here, $R$ is ratio of $\mathrm{NO}_{\mathrm{x}}$ and $\mathrm{NO}_{2}$. This value is considered to be about 1.38 during daytime with an uncertainty of about $10 \%$ according to the measurement results of $\mathrm{Su}$ et al. (2008) in the PRD. The factor $c_{\tau}$ accounts for the destruction of originally emitted $\mathrm{NO}_{\mathrm{x}}$ on the way to measurement location. It depends on the wind speed $(W)$ and measurements distance $(D)$ in the following way:

$c_{\tau}=e^{\frac{D / W}{t}}$.

The $\mathrm{NO}_{\mathrm{x}}$ lifetime $t$ depends, amongst others, on the ozone and $\mathrm{OH}$ concentrations, as well as meteorological conditions. We here take a value of $5 \mathrm{~h}$ (Lin et al., 2010). The resulting $c_{\tau}$ is in the range of 1.10-1.35 assuming an average distance of $9 \mathrm{~km}$ from the emission source to the measurement location. We estimate the uncertainty of $c_{\tau}$ due to the uncertainties of the $\mathrm{NO}_{\mathrm{x}}$ lifetime, wind speed and distance to be about $10-15 \%$.

Wind direction and speed are taken from the miniature mobile weather station installed on the van. The car speed, location, and direction of each segment are from the GPS. The main errors in the estimation of $\mathrm{SO}_{2}$ emission are uncertainties in the VCD retrieval (including uncertainties in the DOAS fit of SCDs and errors due to the conversion from SCDs to VCDs) and wind field (including the uncertainties of wind direction and wind speed). Errors of $\mathrm{NO}_{\mathrm{x}}$ emission calculations include the uncertainties in $R$ and $c_{\tau}$. We estimate the error caused by approximating VCDs by SCDs with radiative transfer calculations of the zenith AMF to be about $10-15 \%$. Taking all the above error estimates into account results in an error for our VCD retrieval of less than $20 \%$ and $25 \%$ for $\mathrm{NO}_{2}$ and $\mathrm{SO}_{2}$, respectively. The wind field is the largest error source not only due to its variation with time and location within the encircled area, but also because of uncertainties of its vertical distribution. The error caused by the wind field is discussed in detail in Sect. 3.2.1.

\section{Results and discussion}

\subsection{Distribution of $\mathrm{SO}_{2}$ and $\mathrm{NO}_{2}$ around GEA}

\subsubsection{Identification of emission sources}

In this section, the distributions of $\mathrm{SO}_{2}$ and $\mathrm{NO}_{2}$ vertical columns along the measurement path are analyzed following the results of the mobile DOAS data described in Sect. 2. The possible emission sources are discussed further using these distributions for different wind fields.

Figure 3 shows the resulting MAX-DOAS VCDs during the measurement period. Figure $3 \mathrm{a}$ and $\mathrm{b}$ also illustrate the mobile DOAS VCDs and the offsets between the two instruments. The average offsets of $\mathrm{SO}_{2}$ and $\mathrm{NO}_{2}$ are $7.83 \pm 1.42 \times 10^{15}$ molec cm $^{-2}$ and $7.02 \pm 2.41 \times 10^{15} \mathrm{molec}^{-2}$, respectively. An example result of $\mathrm{SO}_{2}$ after $\mathrm{SO}_{2}$ offset correction on 25 November is shown in Fig. 3c. Three peaks are also found in Fig. 3a and $\mathrm{b}$. The peaks of $\mathrm{SO}_{2}$ (peak 1, peak 2, peak 3) are related to strong emissions of pollutant sources under the northeasterly wind. The peaks of $\mathrm{NO}_{2}$ (peak 1 and peak 2) on 11 and 29 November are presumably caused by the same pollutant source, but the peak on 21 December (peak 3) may be related to the transport from other regions by the northwesterly wind.

Figure 4a shows the wind direction and wind speed during the whole experimental period. The wind came mostly from the north and northeast with the exception of 21 and 27 November, 5 and 13 December (southeast direction), 30 November and 21 December (northwest), and 4 and 23 December (east). Average wind speed at ground level ranged from $1 \mathrm{~m} \mathrm{~s}^{-1}$ to $5 \mathrm{~m} \mathrm{~s}^{-1}$ during the measurement period. According to the distributions of $\mathrm{SO}_{2}$ and $\mathrm{NO}_{2}$ around the path, four types of wind fields are distinguished in our study: north or northeast, southeast, east, and northwest. 


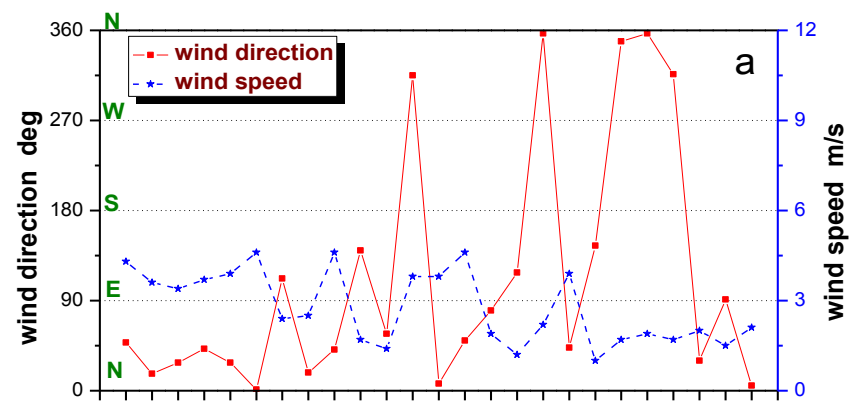

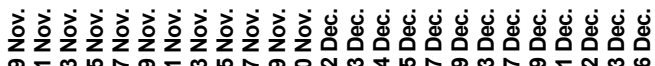

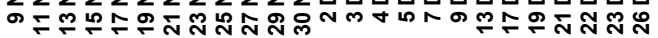

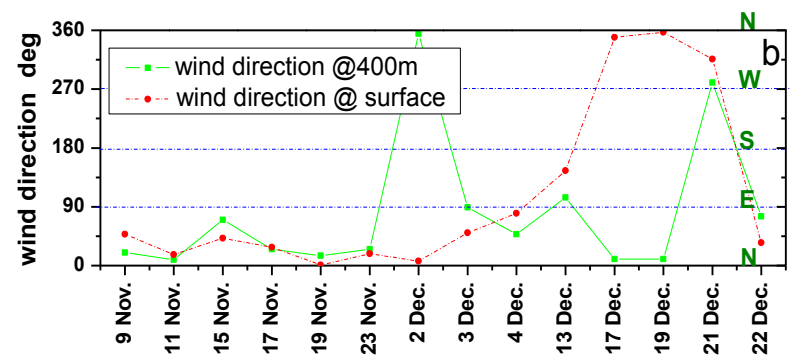

Fig. 4. (a) Time series of average wind direction and wind speed from 10:00 to 13:00 (LT) during the measurement period recorded by our mobile miniature weather station. (b) Comparison of wind direction at surface and $400 \mathrm{~m}$ height. The surface wind fields are from the mobile weather station. The wind field at $400 \mathrm{~m}$ is taken from observations at King's Park (station number: 45004, $114.16^{\circ} \mathrm{E}, 22.31^{\circ} \mathrm{N}$ ) in Hong Kong (http://weather.uwyo. edu/upperair/sounding.html).

Typical spatial distributions of $\mathrm{SO}_{2}$ and $\mathrm{NO}_{2}$ vertical columns around GEA for these four different wind fields are shown in Fig. 5. The maps for $\mathrm{SO}_{2}$ in Fig. 5 show a peak in the north irrespective of wind direction, suggesting an additional emission source outside the GEA and north from it. The comparison for wind direction from north/northeast and east versus west further suggests that it is located in the northeast rather than the northwest. No such peak exists for $\mathrm{NO}_{2}$ in the north if the wind is coming from the north, so that we infer a $\mathrm{SO}_{2}$ source (no dominant $\mathrm{NO}_{2}$ emission) lies in the northeast of GEA (S1 in Fig. 1).

For the southeast wind, downwind peaks are found simultaneously for $\mathrm{SO}_{2}$ and $\mathrm{NO}_{2}$ in the northwest corner of our route (Fig. 5b). The corresponding downwind peaks for the reverse wind direction from the northwest are less pronounced, and thus sources of $\mathrm{NO}_{2}$ and $\mathrm{SO}_{2}$ within the encircled measurement area, but closer to the northern measurement route, can be identified (S2 in Fig. 1). The location of peaks in the downwind region for the north and northeast wind (Fig. 5a and c) is consistent with this conjecture.

Increased values of $\mathrm{NO}_{2}$ appeared for all wind directions in the southeast/south of the measurement route, especially on 29 November and 4 December. These high column densities can most likely be attributed to traffic emissions from
Humen Bridge in the south of GEA (S3 in Fig. 1), the main channel from Shenzhen and Dongguan to Guangzhou. During the Asian Games, the Guangzhou government set up a security checkpoint here, which occasionally caused traffic jams that enhanced high $\mathrm{NO}_{2}$ concentration.

\subsubsection{Comparison with $\mathrm{OMI} \mathrm{NO}_{2}$}

We compare the results from mobile DOAS with OMI observations in this section in two ways. First, the $\mathrm{NO}_{2} \mathrm{VCDs}$ of the mobile DOAS are averaged for all mobile DOAS observations of a given day within one specific ground pixel $\left(113.50^{\circ} \mathrm{E}-113.75^{\circ} \mathrm{E}, 22.75^{\circ} \mathrm{N}-23.00^{\circ} \mathrm{N}\right)$ and compared to OMI values within this pixel. Second, in order to explore spatial patterns, all $\mathrm{NO}_{2}$ VCDs along the measurement path of the mobile DOAS are compared to OMI values on the $0.1^{\circ} \times 0.1^{\circ}$ grid, as specified in Sect. 2.3. Mobile DOAS values were averaged for all measurement days within the pixels of this higher resolved grid.

The comparison of $\mathrm{NO}_{2}$ VCDs between the two instruments for the above-ground pixel is shown in Fig. 6. Our mobile DOAS values were higher than the OMI values most of the time, especially for the measurements from 27 November to 7 December. Aside from the averaged value of OMI for large areas and its insensitivity to the near-surface pollutant sources, the influence of clouds was also considered and treated as a dominant factor for the OMI and mobile DOAS observations.

Cloud fractions for our 14 days of measurement (Table 1) varied considerably during the measurement period. A cloud fraction of 0.4 was used as threshold to filter both data for comparison. This fraction was exceeded on 21, 27, and 29 November, as well as 7 and 9 December. Figure 7 shows the correlation between the two measurements for cloud fractions smaller than 0.4 for the ground pixel $\left(113.50^{\circ} \mathrm{E}-\right.$ $\left.113.75^{\circ} \mathrm{E}, 22.75^{\circ} \mathrm{N}-23.00^{\circ} \mathrm{N}\right)$. The correlation coefficient $\left(R^{2}\right)$ is 0.88 , indicating that relative changes observed by OMI and mobile DOAS were coinciding.

Although both instruments agree in general, high $\mathrm{NO}_{2}$ VCDs were likely underestimated by OMI. These discrepancies, however, cannot be simply attributed to clouds. For example, the 22 and 23 December cloud coverage was lower, yet the discrepancies were higher compared to those of the 11, 19, and 25 November with higher cloud coverage. The disagreement between both data sets could also be caused by different assumptions on the calculation of their air mass factors, including different aerosol and trace gas profiles, ground albedo, etc. Furthermore, mobile and satellite measurements refer to slightly different times. Our mobile DOAS measurements were carried out from 10:00 to 13:00 (LT) and from 11:00 to 12:00(LT) for the area of the satellite pixel $\left(113.50^{\circ} \mathrm{E}-113.75^{\circ} \mathrm{E}, 22.75^{\circ} \mathrm{N}-23.00^{\circ} \mathrm{N}\right)$, while the OMI overpass time was 13:45 (LT). Differences between mobile and OMI observations could therefore, in principle, be due to the diurnal cycle of $\mathrm{NO}_{2}$. From the fact that our LP-DOAS 

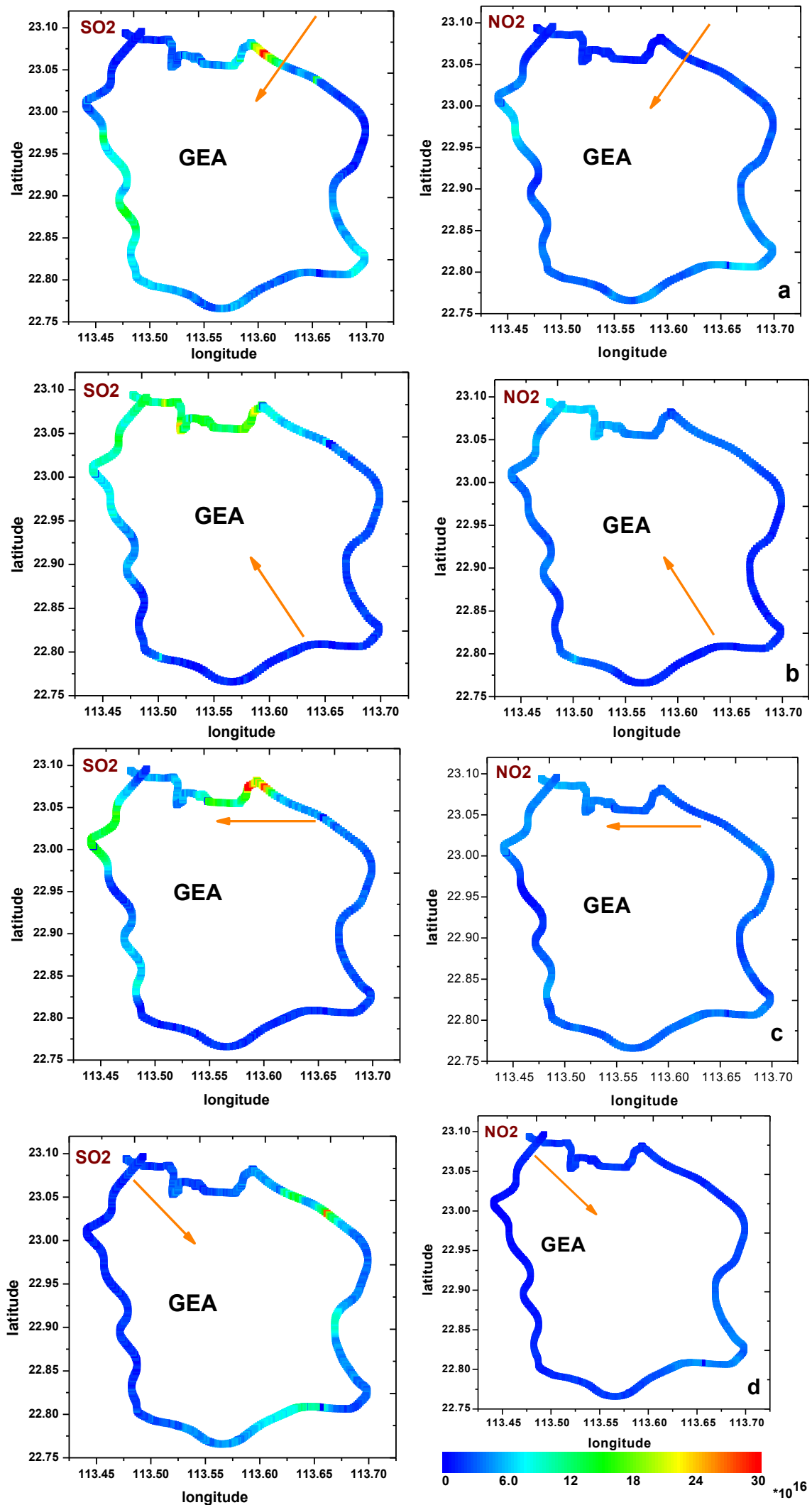

Fig. 5. Examples of $\mathrm{SO}_{2}$ and $\mathrm{NO}_{2}$ vertical columns (units: molec $\mathrm{cm}^{-2}$ ) along the measurement path of the mobile DOAS for four typical wind directions: (a) northeast/north on 29 November, (b) southeast on 5 December, (c) east on 4 December, and (d) northwest 30 November. Arrows indicate the average wind direction. 


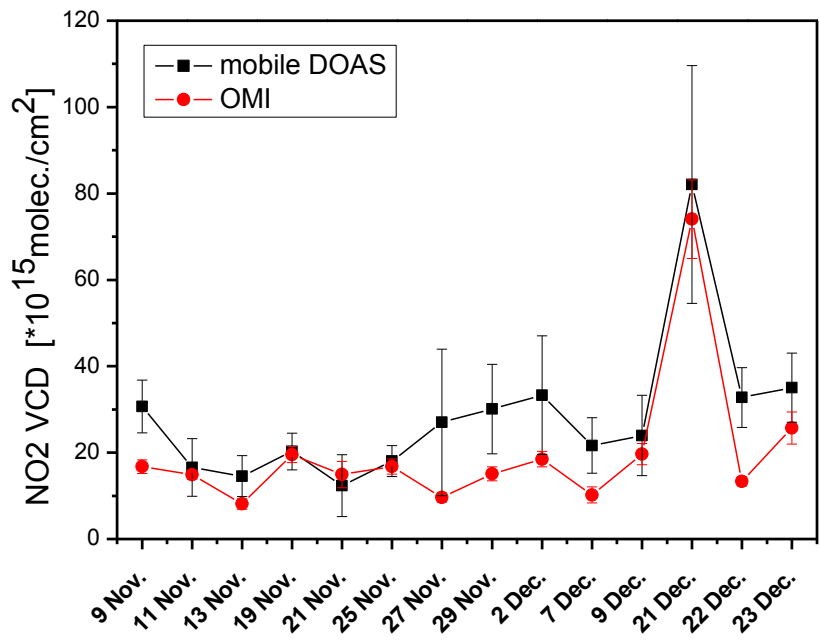

Fig. 6. Time series of $\mathrm{NO}_{2}$ VCDs measured by mobile DOAS (black symbols) and OMI (red symbols) for the satellite ground pixel given by the coordinates $\left(113.50^{\circ} \mathrm{E}-113.75^{\circ} \mathrm{E}, 22.75^{\circ} \mathrm{N}-23.00^{\circ} \mathrm{N}\right)$. The measurement time of the mobile DOAS within this area is from about 11:00 to 12:00 (LT). The bars show the standard deviations of OMI and mobile DOAS as described in the text.

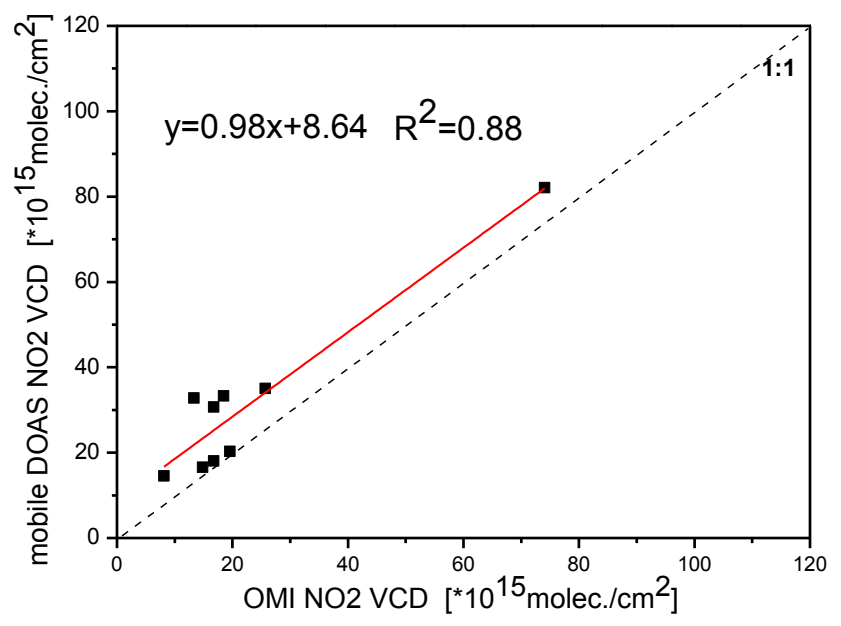

Fig. 7. Correlation between the $\mathrm{OMI}$ and mobile DOAS $\mathrm{NO}_{2}$ VCDs after cloud filtering for the satellite ground pixel $\left(113.50^{\circ} \mathrm{E}-\right.$ $113.75^{\circ} \mathrm{E}, 22.75^{\circ} \mathrm{N}-23.00^{\circ} \mathrm{N}$ ).

observations of $\mathrm{NO}_{2}$ in general show little variation between 11:00 and 13:00 LT, see Fig. 8 (a similar observation was made for Hong Kong in Chan et al., 2012), we conclude that for our case the effect of the daily $\mathrm{NO}_{2}$ cycle between 11:00 and 13:00 LT is of minor importance for this comparison of mobile and satellite measurements.

We now compare spatial patterns as described at the beginning of this section. Figure 9 shows that both mobile DOAS and OMI captured the high $\mathrm{NO}_{2}$ VCDs in the northern and southern part of the mobile DOAS route (in the northern part due to industrial emissions, in the southern part due to vehicle emissions from the Humen Bridge), as well as low VCDs
Table 1. Cloud fraction for the 14 days of measurement. Italic text represents the cloud fraction $<0.4$. Bold text represents the cloud fraction $>0.4$. Cloud fractions are taken from the OMI data product.

\begin{tabular}{cc}
\hline Date & Cloud fraction \\
\hline 9 Nov & 0.24 \\
11 Nov & 0.20 \\
13 Nov & 0.37 \\
19 Nov & 0.11 \\
25 Nov & 0.15 \\
2 Dec & 0.25 \\
21 Dec & 0.18 \\
22 Dec & 0.06 \\
23 Dec & 0.01 \\
\hline 21 Nov & $\mathbf{0 . 6 6}$ \\
27 Nov & $\mathbf{0 . 5 6}$ \\
29 Nov & $\mathbf{0 . 4 1}$ \\
7 Dec & $\mathbf{0 . 6 3}$ \\
9 Dec & $\mathbf{0 . 5 0}$ \\
\hline
\end{tabular}

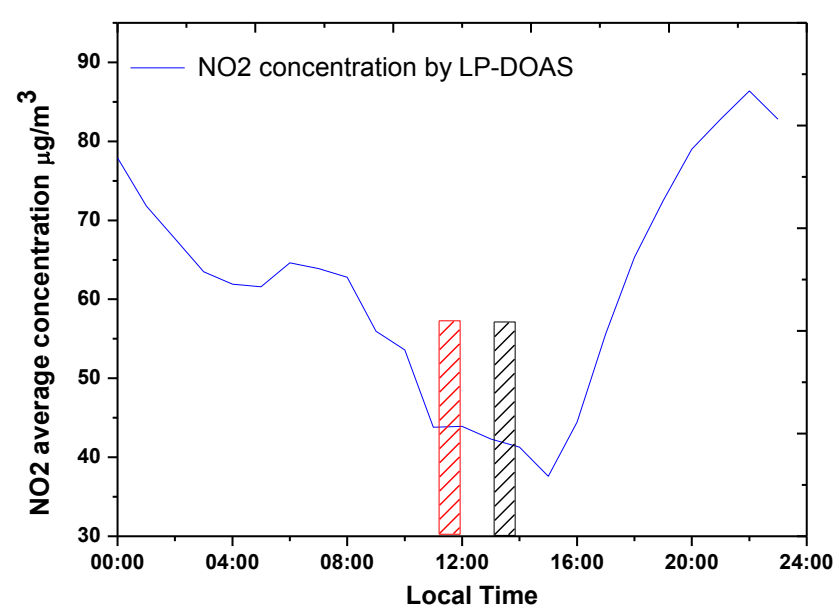

Fig. 8. Mean daily $\mathrm{NO}_{2}$ cycle of the LP-DOAS from 11 November to 25 December 2010, at Guangzhou University Town site. The black hatched region indicates the OMI overpass time for Guangzhou. The red hatched region indicates the time when the mobile DOAS traverses the area of the satellite ground pixel $\left(113.50^{\circ} \mathrm{E}-113.75^{\circ} \mathrm{E}, 22.75^{\circ} \mathrm{N}-23.00^{\circ} \mathrm{N}\right)$.

in the western part (white circles in Fig. 9). The correlation analysis for these three areas (indicated by white circles in Fig. 9) is shown in Fig. 10. The correlation coefficient $\left(R^{2}\right)$ is 0.72 , suggesting that both observations indeed agree reasonably well. However, no such agreement can be found when all grid cells are taken into account. One reason for the lack of correlation might be that data are compared for the same location, but not the same time. Comparing two values for times when the diurnal variation cannot be neglected inevitably leads to mismatch between both data sets. According to Fig. 8, strong diurnal changes of $\mathrm{NO}_{2}$ occur between 10:00 and 11:00 LT. During this time, mobile DOAS observa- 


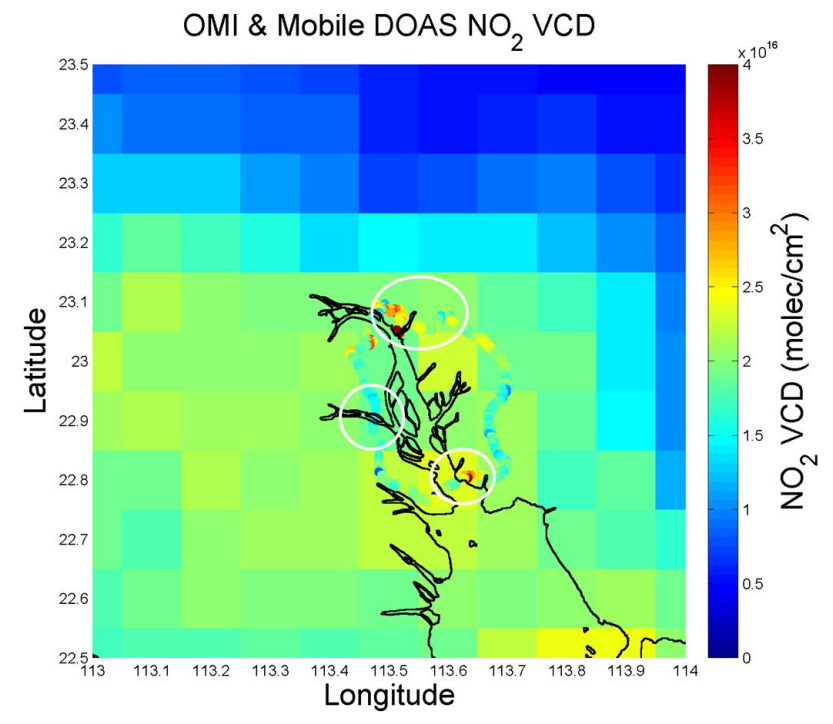

Fig. 9. Comparison of $\mathrm{NO}_{2} \mathrm{VCD}$ patterns measured by mobile DOAS and OMI (ground pixel: $113.25^{\circ} \mathrm{E}-113.75^{\circ} \mathrm{E}, 22.75^{\circ} \mathrm{N}-$ $23.25^{\circ} \mathrm{N}$ ) during the whole measurement period (9 November to 23 December 2010). The color-coded circle indicates the mobile DOAS observations. The white circles in the northern and southern part show particularly high $\mathrm{NO}_{2}$ values captured by both instruments. The white circle in the western part contains low $\mathrm{NO}_{2}$ values for both instruments. The grid resolution is $0.1^{\circ} \times 0.1^{\circ}$.

tions were carried out in the eastern part of the GEA. Lacking further data from longer measurements or models, we do not attempt a correction of this mismatch, but notice that it might have significant influence even for the relatively limited time of our mobile measurements.

\subsection{Estimation of $\mathrm{SO}_{2}$ and $\mathrm{NO}_{\mathrm{x}}$ emissions}

\subsubsection{Emission of $\mathrm{SO}_{2}$ and $\mathrm{NO}_{\mathrm{x}}$ from GEA}

As a key component in the estimation of $\mathrm{SO}_{2}$ and $\mathrm{NO}_{\mathrm{x}}$ emissions, wind fields can be the source of large errors. Wind fields are generally used to estimate emissions about $400 \mathrm{~m}$ above ground level (according to the stack height of a power plant and the height of an elevated plume as discussed by Mellqvist et al., 2007). A wind profile radar could provide highly accurate data, but was not available for our measurements. Wind data from our mobile weather station are used instead. To minimize the error caused by the influence of surface processes on the wind field, measurement days with relatively constant wind field from ground to $400 \mathrm{~m}$ height are selected to estimate emissions. Figure $4 \mathrm{~b}$ compares the wind direction at $400 \mathrm{~m}$ height to the surface from 9 November to 22 December. The wind field at $400 \mathrm{~m}$ is taken from observations at Kings Park (station number: $45004,114.16^{\circ} \mathrm{E}$, $22.31^{\circ} \mathrm{N}$ ) in Hong Kong, about $80 \mathrm{~km}$ southeast of GEA (http://weather.uwyo.edu/upperair/sounding.html). With few exceptions, Fig. 4b illustrates that the wind direction at both

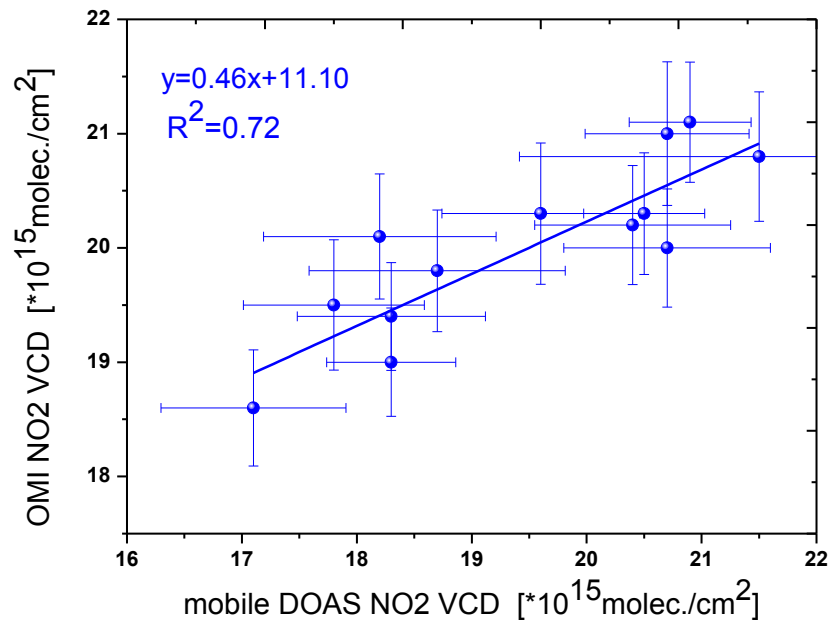

Fig. 10. Correlation analysis of OMI and mobile DOAS $\mathrm{NO}_{2} \mathrm{VCDs}$ for the three areas (white circles) in Fig. 9. Values are averaged over the whole measurement period for both instruments.

altitudes generally agree, with a relative deviation of $\sim 30^{\circ}$. Based on this variation, we estimate the error of our emissions due to change of wind direction with height to be $20 \%$. While the wind direction in the higher atmosphere might vary little over a relatively small area, the wind speed can change significantly for different locations. We do not take into account differences in the wind speed profiles between different locations. Instead, the ratio of wind speeds at $400 \mathrm{~m}$ to that at ground level was estimated to be $1.2-1.3$ according to the national standard (GB/T 3840-91) from the environmental protection agency of China (Ministry of Environmental Protection of the People's Republic of China, 1992). So we simply use the wind speed at ground to estimate emission errors caused by uncertainties in the wind speed profile and arrive at a value of about $20-30 \%$.

Total emissions of $\mathrm{SO}_{2}$ and $\mathrm{NO}_{\mathrm{x}}$ from the encircled GEA area obtained from Eq. (2) are shown in Fig. 11 for 14 days with a fractional cloud cover lower than 0.4 and a constant wind field. The entire measurement period is divided into five phases: before the Asian Games ( 9 and 11 November, phase 1), during the Asian Games (15, 17, 19, and 23 November, phase 2), the time between the Asian Games and the Asian Para Games (2, 3, and 4 December, phase 3), during the Asian Para Games (13, 17, and 19 December, phase 4), and after the games (21 and 22 December, phase 5). $\mathrm{SO}_{2}$ emissions varied strongly between the different phases (by a factor of 5), where the lower and lowest emissions occurred during the Asian Games and Asian Para Games, respectively. A clear pattern for $\mathrm{NO}_{\mathrm{x}}$ emissions was not found, although these emissions decreased at the beginning of the games and increased again after their end.

The reduced emission of $\mathrm{SO}_{2}$ during the Asian Games and Asian Para Games could be caused mainly by the pollution control strategy of the local environmental protection agency. 
Table 2. $\mathrm{SO}_{2}$ and $\mathrm{NO}_{\mathrm{x}}$ emissions as measured by our mobile DOAS for the different phases described in the text.

\begin{tabular}{lcccccc}
\hline & \multicolumn{5}{c}{ Emission ton $^{-1}$} \\
& Phase 1 & Phase 2 & Phase 3 & Phase 4 & Phase 5 & Phase 1+3+5 \\
\hline $\mathrm{SO}_{2}$ & $9.39 \pm 1.06$ & $6.38 \pm 0.72$ & $9.93 \pm 0.15$ & $2.45 \pm 0.15$ & $8.97 \pm 1.58$ & $9.50 \pm 0.90$ \\
$\mathrm{NO}_{\mathrm{x}}$ & $7.20 \pm 2.25$ & $3.41 \pm 1.14$ & $2.78 \pm 0.64$ & $3.22 \pm 1.04$ & $9.19 \pm 3.47$ & $5.87 \pm 3.46$ \\
\hline
\end{tabular}

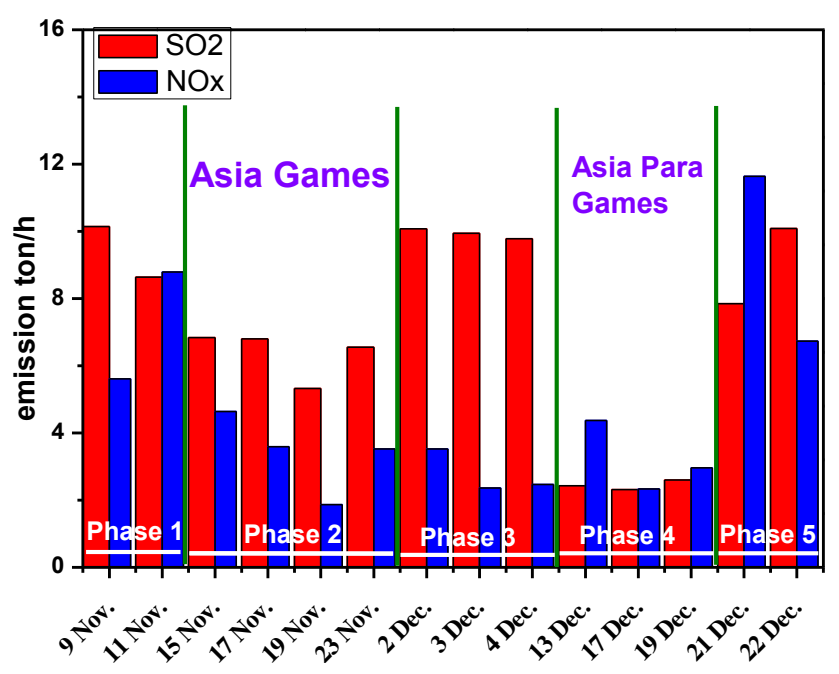

Fig. 11. $\mathrm{SO}_{2}$ and $\mathrm{NO}_{\mathrm{x}}$ emissions estimated from mobile DOAS measurements between 10:00 to 13:00 (LT). Green lines indicate the beginning and end of the Asian and Asian Para Games.

Meteorological conditions also play an important role for emissions from GEA. Persistent rainfall from 10 to 12 December and again from 14 to 16 December helped to remove air pollutants, thereby decreasing emissions from GEA during the Asian Para Games. Table 2 summarizes the average $\mathrm{SO}_{2}$ emission for the different phases of the measurement period. For times outside the games (phases 1, 3, and 5), $\mathrm{SO}_{2}$ emission was estimated to be 9.50 tons per hour (approximately $83.2 \times 10^{3}$ tons per year), which is consistent with the value of $84.60 \times 10^{3}$ tons per year from the emission inventory (Guangzhou Municipality State of the Environment, 2010). On the other hand, the average $\mathrm{NO}_{\mathrm{x}}$ emission for this time was estimated to be 5.87 tons per hour. During the games (including phases 2 and 4 ) the emissions of $\mathrm{SO}_{2}$ and $\mathrm{NO}_{\mathrm{x}}$ from GEA were reduced by $53.50 \%$ and $43.50 \%$, respectively, compared with the time outside the games (including phases 1,3 , and 5).

Errors in the calculation of emissions are due to errors in the VCD retrieval, wind field, and car speed. The total error in the VCD retrieval was estimated to be less than $20 \%$ for $\mathrm{NO}_{2}$ and $25 \%$ for $\mathrm{SO}_{2}$. The error of the car speed was about $1 \%$ according to the GPS. The errors caused by wind direction and wind speed were about $20 \%$ and $20-30 \%$, respectively, or about 30-35\% together. The total error for the estimate of $\mathrm{SO}_{2}$ emissions amounts to about $35-40 \%$. Addi- tional uncertainties caused by $R$ and $c_{\tau}$ of $10 \%$ and $10-15 \%$, result in a total error of $\mathrm{NO}_{\mathrm{x}}$ emissions of about $40-45 \%$.

\subsubsection{Influence of $\mathrm{SO}_{2}$ emissions from the GEA on the downwind region}

Knowledge of emissions and transport from large area sources is crucial for the control and management of local environment problems. Guangzhou University Town $\left(23.05^{\circ} \mathrm{N}, 113.37^{\circ} \mathrm{E}\right)$ hosted numerous events during the Asian Games, which raised issues on the air quality of the town. According to the geographical relationship between GEA and Guangzhou University Town from Fig. 1, the pollutants from GEA can diffuse to Guangzhou University Town when the wind direction is southeast. The $\mathrm{SO}_{2}$ concentration in Guangzhou University Town is expected to increase due to the contribution of GEA emission. $\mathrm{SO}_{2}$ is selected as the tracer gas because it originates from industrial emissions, unlike $\mathrm{NO}_{2}$ which is still affected by local vehicle emissions. To investigate how emissions from GEA affect Guangzhou University Town for southeasterly winds, a long-path DOAS instrument is set up there to monitor possible downwind transport of $\mathrm{SO}_{2}$.

The paths of air masses for southeasterly wind on 21 and 27 November, and 5 and 13 December are shown in Fig. 12. On these days, the wind traversed GEA and the $\mathrm{SO}_{2}$ concentrations measured downwind at the University Town monitoring site by our long-path instrument were significantly higher, as illustrated in Fig. 13 (shaded box). Similar phenomena can be observed on 24 and 28 November and 10 and 12 December in Fig. 13, when the wind was also coming from the southeast. The average $\mathrm{SO}_{2}$ concentrations for southeasterly and non-southeasterly winds measured by the long-path DOAS at the downwind location are $72.55 \pm 13.06 \mu \mathrm{g} \mathrm{m}^{-3}$ and $24.58 \pm 11.72 \mu \mathrm{g} \mathrm{m}^{-3}$, respectively. Daily averages of $\mathrm{SO}_{2}$ are enhanced by a factor 3 when air masses traversed GEA, compared to days when the wind came from other directions. Therefore, GEA is concluded to be a major contributor to $\mathrm{SO}_{2}$ pollution in the Guangzhou University Town area.

\section{Conclusions}

In this paper, mobile DOAS observations carried out in GEA during the Guangzhou Asian Games from November to December 2010 are reported. These measurements were used 


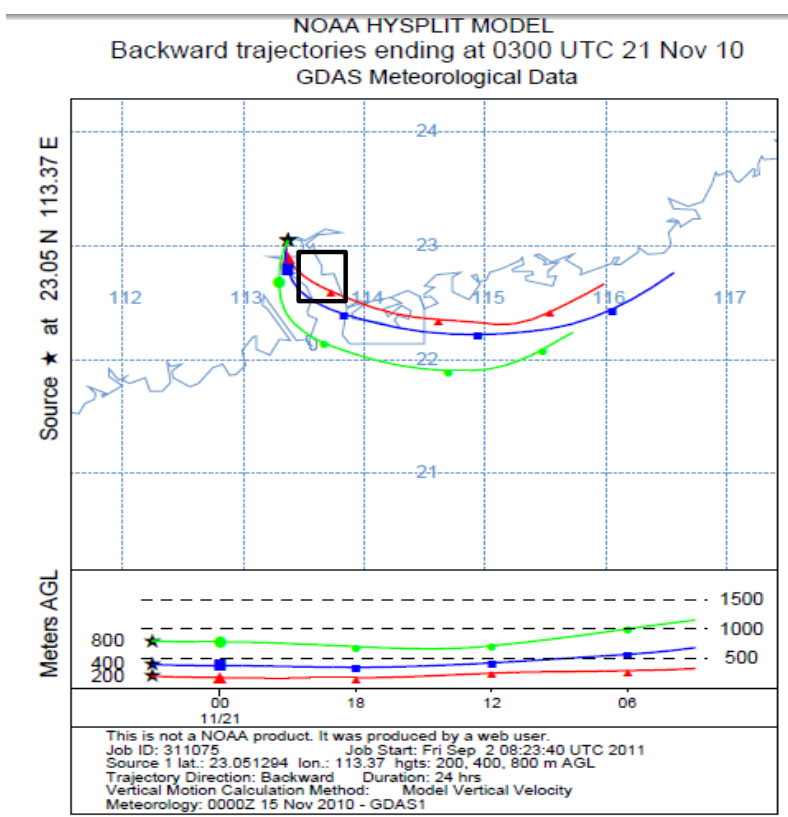

a

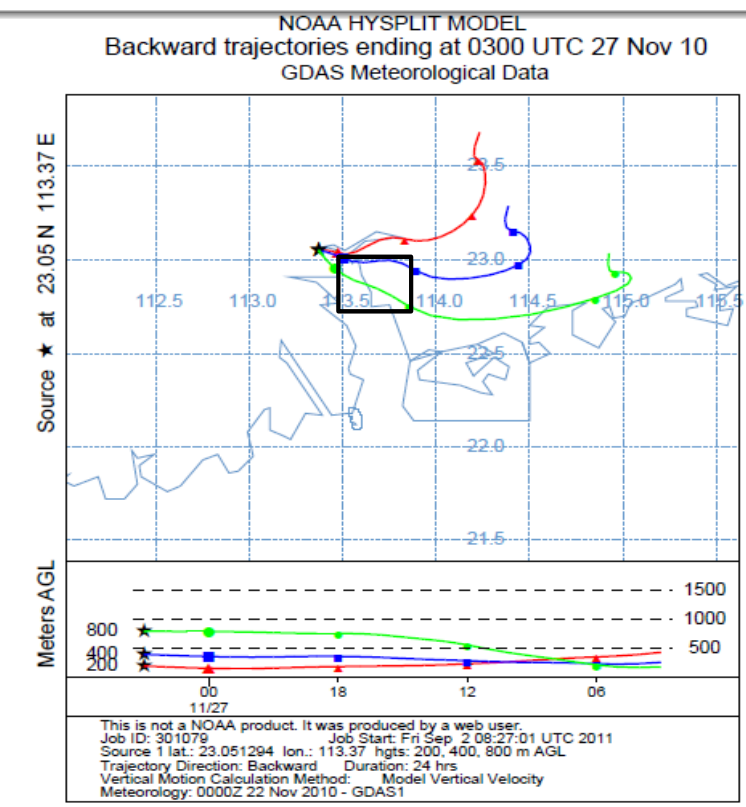

NOAA HYSPLIT MODEL

Backward trajectories ending at 0300 UTC 05 Dec 10 GDAS Meteorological Data
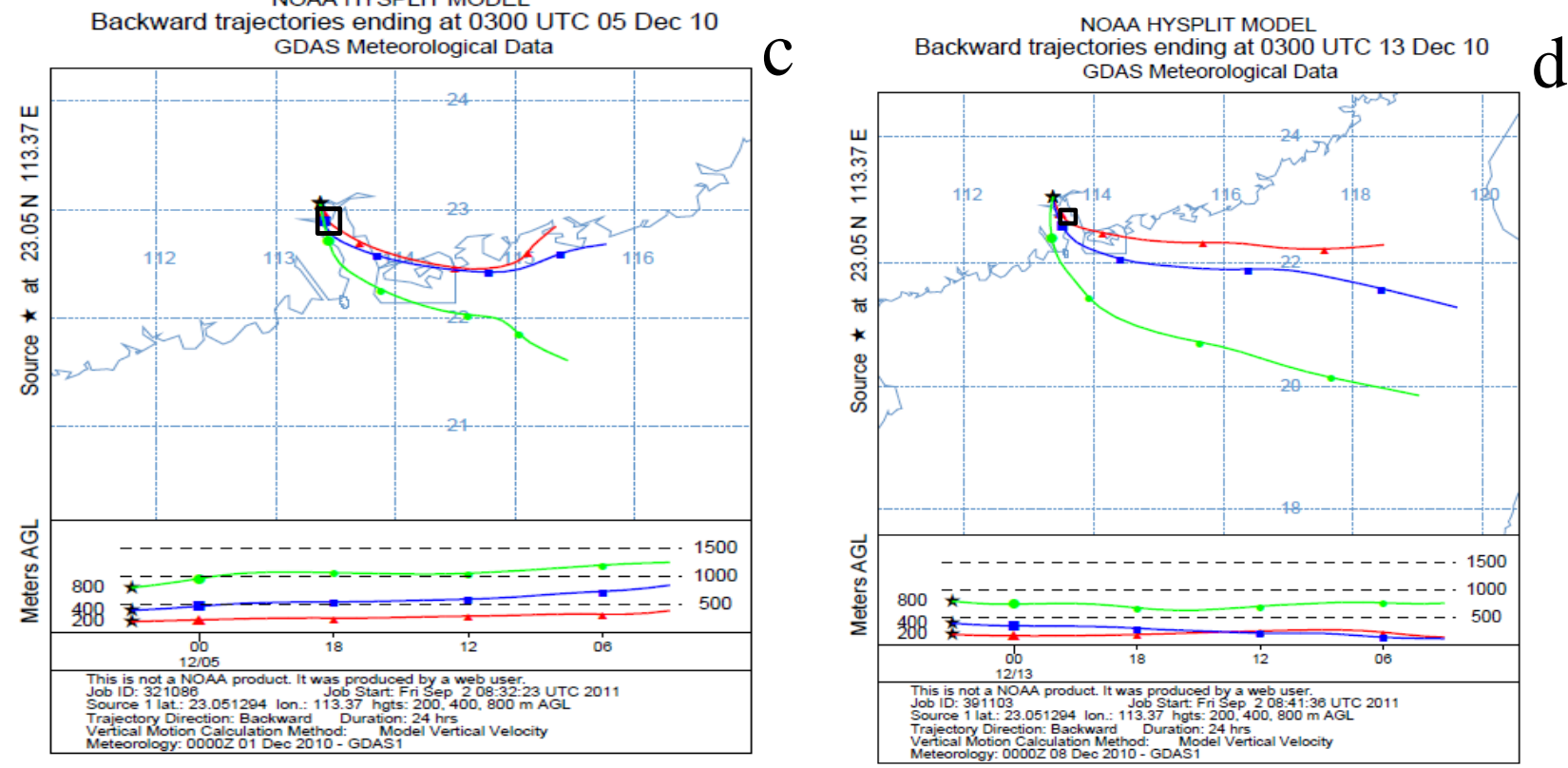

Fig. 12. Backward wind trajectories for the $200 \mathrm{~m}$ (red), $400 \mathrm{~m}$ (blue), and $800 \mathrm{~m}$ (green) heights at the Guangzhou University Town monitoring site from the NOAA HYSPLIT model (http://www.arl.noaa.gov/index.php) on 21 (a) and 27 (b) November, and 5 (c) and 13 (d) December. The star indicates the Guangzhou University Town monitoring site, the black box the measurement area of the mobile DOAS measurement.

to investigate the spatial and temporal distributions of $\mathrm{SO}_{2}$ and $\mathrm{NO}_{2}$ around and emissions from GEA during the Asian Games period.

A MAX-DOAS instrument at a fixed location concurrently measured estimates of absolute vertical columns for $\mathrm{NO}_{2}$ and $\mathrm{SO}_{2}$ of the mobile DOAS measurements. The average offsets of $\mathrm{SO}_{2}$ and $\mathrm{NO}_{2}$ between the mobile DOAS and MAX-DOAS were $7.83 \pm 1.42 \times 10^{15} \mathrm{molec}^{-2}$ and $7.02 \pm 2.41 \times 10^{15}$ molec cm $^{-2}$, respectively.

Distributions of $\mathrm{SO}_{2}$ and $\mathrm{NO}_{2}$ vertical columns were obtained with help of the mobile DOAS system. High $\mathrm{SO}_{2}$ values appeared in the northeast and northwest of our measurement path under north and southeast wind fields, respectively. High $\mathrm{NO}_{2}$ values were found in the north and southeast of the measurement path with higher variability due to 


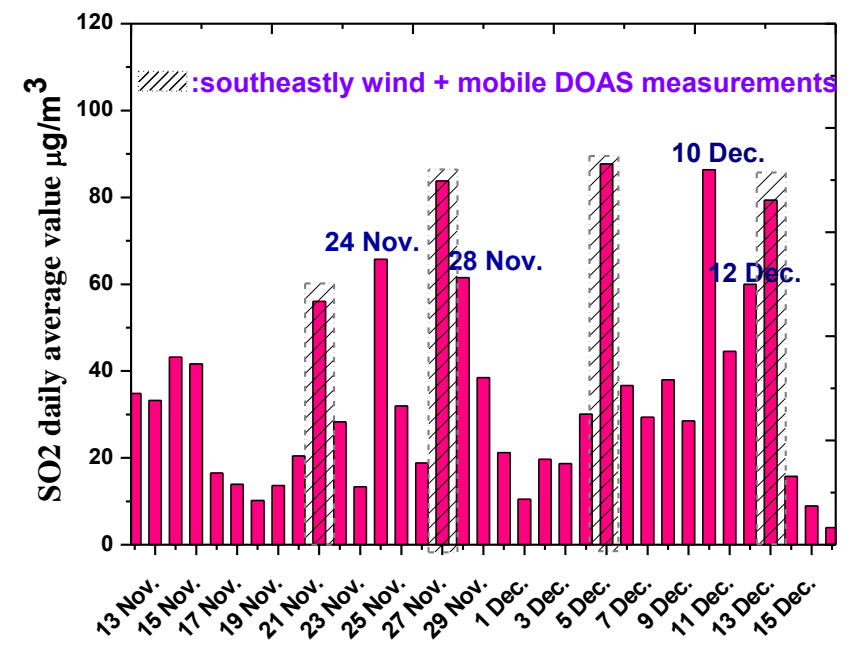

Fig. 13. Daily average $\mathrm{SO}_{2}$ concentrations measured by long-path DOAS at the Guangzhou University Town site. The shaded days indicate days when the wind came from the southeast and mobile DOAS measurements were conducted. For days with similar wind situations on 24 and 28 November and 10 and 12 December, we could not conduct mobile DOAS measurements due to vehicle limitation.

varying traffic emissions. Possible emission sources were determined to explain these distributions using the information from different wind fields. Pollutant sources in the northeast of GEA, outside the closed measurement route and sources in the north, within the area encircled, were also identified. Our $\mathrm{NO}_{2}$ vertical columns were compared with OMI data and were found to be similar in spatial patterns. The correlation coefficient $\left(R^{2}\right)$ of the vertical columns after cloud filtering was 0.88 within a specific ground pixel, but the absolute values measured by our mobile DOAS were mostly higher than the OMI data. $\mathrm{SO}_{2}$ and $\mathrm{NO}_{\mathrm{x}}$ emissions from the GEA during the Asian Games period were also calculated. Lower and lowest emissions of $\mathrm{SO}_{2}$ were found to occur during the Asian Games and Asian Para Games, respectively. Outside the Asian Games period, the average emission of $\mathrm{SO}_{2}$ was estimated to be $9.50 \pm 0.90$ tons per hour ( 83.2 thousand tons per year), which is consistent with the value of 84.6 thousand tons per year from a local emission inventory. In comparison, the average emission of $\mathrm{NO}_{\mathrm{x}}$ was estimated to be $5.87 \pm 3.46$ tons per hour. During the games, the emissions of $\mathrm{SO}_{2}$ and $\mathrm{NO}_{\mathrm{x}}$ were reduced by $53.50 \%$ and $43.50 \%$, respectively. The error of total emissions was estimated to be about $40-45 \%$ for $\mathrm{NO}_{\mathrm{x}}$ and $35-40 \%$ for $\mathrm{SO}_{2}$. Using LPDOAS measurements at the Guangzhou University Town, emissions from GEA were found to have a distinct impact on air pollution in this area depending on the wind direction. $\mathrm{SO}_{2}$ concentrations were found to be about three times larger during our measurements when air masses crossed GEA.
Acknowledgements. The authors would like to thank the Guangzhou Environmental Center for supporting the experiment. We also want to thank our two drivers, Shaoli Wang and Zongmao $\mathrm{Xu}$, whose skillful driving ensured that the experiment could be carried out successfully and safely. This work was also made possible by the support of special research funding for the public industry sponsored by Ministry of Environmental Protection of PRC (Grant No: 201109007), the National Natural Science Foundation of China 40905010, 41275038 and the Anhui Province Natural Science Foundation of China 1308085QF124.

Edited by: J. Stutz

\section{References}

Bogumil, K., Orphal, J., Homann, T., Voigt, S., Spietz, P., Fleischmann, O. C., Vogel, A., Hartmann,M., Kromminga, H., Bovensmann, H., Frerick, J., and Burrows, J. P.: Measurements of molecular absorption spectra with the SCIAMACHY preflight model: instrument characterization and reference data for atmospheric remote-sensing in the $230-2380 \mathrm{~nm}$ region, J. Photoch. Photobio. A, 157, 167-184, 2003.

Bucsela, E., Celarier, E., Wenig, M., Gleason, J., Veefkind, P., Boersma, K., and Brinksma, E.: Algorithm for $\mathrm{NO}_{2}$ vertical column retrieval from the Ozone Monitoring Instrument, IEEE T. Geosci. Remote, 44, 1245-1258, 2006.

Cao, J. J., Lee, S. C., Ho, K. F., Zou, S. C., Fung, K., Li, Y., Watson, J. G., and Chow, J. C.: Spatial and seasonal variations of atmospheric organic carbon and elemental carbon in Pearl River Delta Region, China, Atmos. Environ., 38, 4447-4456, 2004.

Chan, K. L., Pöhler, D., Kuhlmann, G., Hartl, A., Platt, U., and Wenig, M. O.: $\mathrm{NO}_{2}$ measurements in Hong Kong using LED based long path differential optical absorption spectroscopy, Atmos. Meas. Tech., 5, 901-912, doi:10.5194/amt-5-901-2012, 2012.

Chen, Z. Y., Liu, W. Q., Zhang, Y. J., He, J. F., and Ruan, J.: Mixing layer height and meteorological measurements in Hefei China during the total solar eclipse of 22 July, 2009, Opt. Laser Technol., 43, 50-54, 2011.

Dix, B., Brenninkmeijer, C. A. M., Frieß, U., Wagner, T., and Platt, U.: Airborne multi-axis DOAS measurements of atmospheric trace gases on CARIBIC long-distance flights, Atmos. Meas. Tech., 2, 639-652, doi:10.5194/amt-2-639-2009, 2009.

Edner, H., Ragnarson, P., Svanberg, S., Wallinder, E., Ferrara, R., Cioni, R., Raco, B., and Taddeucci, G.: Total fluxes of sulfur dioxide from the Italian volcanoes Etna, Stromboli, and Vulcano measured by differential absorption lidar and passive differential optical absorption spectroscopy, J. Geophys. Res., 99, 1882718838, 1994.

Finlayson-Pitts, B. J. and Pitts, J. N.: Chemistry of the Upper and Lower Atmosphere: Theory, Experiments, and Applications, Academic Press, San Diego, USA, 1999.

Galle, B., Oppenheimer, C., Geyer, A., McGonigle, A. J. S., Edmonds, M., and Horrocks, L.: A miniaturised ultraviolet spectrometer for remote sensing of $\mathrm{SO}_{2}$ fluxes: a new tool for volcano surveillance, J. Volcanol. Geoth. Res., 119, 241-254, 2003.

Greenblatt, G. D., Orlando, J. J., Burkholder, J. B., and Ravishankara, A. R.: Absorption measurements of oxygen between 
$330 \mathrm{~nm}$ and $1140 \mathrm{~nm}$, J. Geophys. Res.-Atmos., 95, 1857718582, doi:10.1029/JD095iD11p18577, 1990.

Guangzhou Environmental Protection, Guangzhou Municipality State of the Environment, available at: http://www.gzepb.gov.cn/ zwgk/hjgb/201106/t2011060766789.htm, (last access: January 2013), 2010.

He, M., Zheng, J. Y., Yin, S. S., and Zhang, Y. Y.: Trends, temporal and spatial characteristics, and uncertainties in biomass burning emissions in the Pearl River Delta, China, Atmos. Environ., 45, 4051-4059, 2011.

Heue, K.-P., Brenninkmeijer, C. A. M., Baker, A. K., RautheSchöch, A., Walter, D., Wagner, T., Hörmann, C., Sihler, H., Dix, B., Frieß, U., Platt, U., Martinsson, B. G., van Velthoven, P. F. J., Zahn, A., and Ebinghaus, R.: $\mathrm{SO}_{2}$ and $\mathrm{BrO}$ observation in the plume of the Eyjafjallajökull volcano 2010: CARIBIC and GOME-2 retrievals, Atmos. Chem. Phys., 11, 2973-2989, doi:10.5194/acp-11-2973-2011, 2011.

Hönninger, G., von Friedeburg, C., and Platt, U.: Multi axis differential optical absorption spectroscopy (MAX-DOAS), Atmos. Chem. Phys., 4, 231-254, doi:10.5194/acp-4-231-2004, 2004.

Ibrahim, O., Shaiganfar, R., Sinreich, R., Stein, T., Platt, U., and Wagner, T.: Car MAX-DOAS measurements around entire cities: quantification of $\mathrm{NO}_{\mathrm{x}}$ emissions from the cities of Mannheim and Ludwigshafen (Germany), Atmos. Meas. Tech., 3, 709-721, doi:10.5194/amt-3-709-2010, 2010.

Johansson, M., Galle, B., Yu, T., Tang, L., Chen, D. L., Li, H. J., Li, J. X., and Zhang, Y.: Quantification of total emission of air pollutants from Beijing using mobile mini-DOAS, Atmos. Environ., 42, 6926-6933, 2008.

Johansson, M., Rivera, C., de Foy, B., Lei, W., Song, J., Zhang, Y., Galle, B., and Molina, L.: Mobile mini-DOAS measurement of the outflow of $\mathrm{NO}_{2}$ and $\mathrm{HCHO}$ from Mexico City, Atmos. Chem. Phys., 9, 5647-5653, doi:10.5194/acp-9-5647-2009, 2009.

Kneizys, F. X., Shettle, E. P., Abreu, L. W., Chetwynd, J. H., and Anderson, G. P.: Users Guide to LOWTRAN7, Air Force Geophysics Laboratory, Hanscom AFB, MA, USA, 1988.

Kraus, S.: DOASIS, A Framework Design for DOAS, PhD-thesis, University of Mannheim, Shaker Verlag, Heidelberg, Germany, 2006.

Kurucz, R. L., Furenlid, I., Brault, J., and Testerman, L.: Solar flux atlas from $296 \mathrm{~nm}$ to $1300 \mathrm{~nm}$, National Solar Observatory Atlas No. 1, Office of University publisher, Harvard University, Cambridge, 1984.

Levelt, P. F., van den Oord, G. H. J., and Dobber, M. R.: The ozone monitoring instrument, IEEE T. Geosci. Remote, 44, 1093-1101, 2006.

Li, A., Liu, C., Xie, P. H., Liu, J. G., Qin, M., Dou, K., Fang, W., and Liu, W. Q.: Monitoring of $\mathrm{SO}_{2}$ emissions from industry by passive DOAS, Proc. SPIE, 5832, 0277-786X/05/\$15, 10, doi:10.1117/12.619651, 2005.

Li, A., Xie, P. H., and Liu, W. Q.: Monitoring of total emission volume from pollution sources based on passive differential optical absorption spectroscopy, Acta Opt. Sin., 27, 1537-1542, 2007a.

Li, A., Xie P. H., Liu, C., Liu J. G., and Liu W. Q.: A scanning multi-axis differential optical absorption spectroscopy system for measurement of tropospheric $\mathrm{NO}_{2}$ in Beijing, Chin. Phys. Lett., 24, 2859-2862, 2007b.

Lin, J.-T., McElroy, M. B., and Boersma, K. F.: Constraint of anthropogenic $\mathrm{NO}_{\mathrm{x}}$ emissions in China from different sectors: a new methodology using multiple satellite retrievals, Atmos. Chem. Phys., 10, 63-78, doi:10.5194/acp-10-63-2010, 2010.

Louisa, J. K., Roland, J. L., John, J. R., and Paul, S. M.: Comparison of OMI and ground-based in situ and MAX-DOAS measurements of tropospheric nitrogen dioxide in an urban area, J. Geophys. Res., 113, D16S39, doi:10.1029/2007JD009168, 2008.

Melamed, M. L., Basaldud, R., Steinbrecher, R., Emeis, S., RuízSuárez, L. G., and Grutter, M.: Detection of pollution transport events southeast of Mexico City using ground-based visible spectroscopy measurements of nitrogen dioxide, Atmos. Chem. Phys., 9, 4827-4840, doi:10.5194/acp-9-4827-2009, 2009.

Mellqvist, J., Samuelsson, J., and Rivera, C.: Measurements of industrial emissions of VOCs, $\mathrm{NH}_{3}, \mathrm{SO}_{2}$ and $\mathrm{NO}_{2}$ in Texas using the solar occultation flux method and mobile DOAS, Final Report HARC Project H-53, Radio and Space Science Chalmers University of Technology, Goteborg, Sweden, 2007.

Ministry of Environmental Protection of the People's Republic of China: Technical methods for making local emission standards of air pollutants (GB/T 3840-91), available at: http://kjs.mep.gov. cn/hjbhbz/bzwb/other/qt/199206/t19920601_67580.htm, 1992

Platt, U. and Stutz, J.: Differential Optical Absorption Spectroscopy: Principles and Applications, Springer, Heidelberg, Germany, 2008.

Qin, M., Xie, P. H., Liu, W. Q., Li, A., Dou, K., Fang,W., Liu, H. G., and Zhang, W. J.: Observation of atmospheric nitrous acid with DOAS in Beijing, J. Environ. Sci.-China, 18, 69-75, 2006.

Rivera, C., Sosa, G., Wöhrnschimmel, H., de Foy, B., Johansson, M., and Galle, B.: Tula industrial complex (Mexico) emissions of $\mathrm{SO}_{2}$ and $\mathrm{NO}_{2}$ during the MCMA 2006 field campaign using a mobile mini-DOAS system, Atmos. Chem. Phys., 9, 6351-6361, doi:10.5194/acp-9-6351-2009, 2009.

Rozanov, V. V., Buchwitz, M., Eichmann, K. U., de Beek, R., and Burrows, J. P.: Sciatran - a new radiative transfer model for geophysical applications in the $240-2400 \mathrm{~nm}$ spectral region: the pseudo-spherical version, Adv. Space Res., 29, 1831-1835, 2002.

Shaiganfar, R., Beirle, S., Sharma, M., Chauhan, A., Singh, R. P., and Wagner, T.: Estimation of $\mathrm{NO}_{\mathrm{x}}$ emissions from Delhi using Car MAX-DOAS observations and comparison with OMI satellite data, Atmos. Chem. Phys., 11, 10871-10887, doi:10.5194/acp-11-10871-2011, 2011.

Sluis, W. W., Allaart, M. A. F., Piters, A. J. M., and Gast, L. F. L.: The development of a nitrogen dioxide sonde, Atmos. Meas. Tech., 3, 1753-1762, doi:10.5194/amt-3-1753-2010, 2010.

Stutz, J., Kim, E. S., Platt, U., Bruno, P., Perrino, C., and Febo, A.: UV-visible absorption cross sections of nitrous acid, J. Geophys. Res-Atmos., 15, 14585-14592, 2000.

Su, H., Cheng, Y. F., Cheng, P., Zhang Y. H., Dong, S. F., Zeng, L. M., Wang, X. S., Slanina, J., Shao, M., and Wiedensohler, A., Observation of nighttime nitrous acid (HONO) formation at a non-urban site during PRIDE-PRD2004 in China, Atmos. Environ., 42, 6219-6232, 2008.

Takashima, H., Irie, H., Kanaya, Y., and Akimoto, H.: Enhanced $\mathrm{NO}_{2}$ at Okinawa Island, Japan caused by rapid air-mass transport from China as observed by MAX-DOAS, Atmos. Environ., 45, 2593-2597, 2011.

US government printing office: US Standard Atmosphere, 1976, Washington, DC, October 1976. 
Van Roozendael, C. F.: WinDOAS 2.1 Software User Manual, IASB/BIRA, Brussel, Belgium, 2001.

Wagner, T., Ibrahim, O., Shaiganfar, R., and Platt, U.: Mobile MAX-DOAS observations of tropospheric trace gases, Atmos. Meas. Tech., 3, 129-140, doi:10.5194/amt-3-129-2010, 2010.

Wang, W., Ren, L. H., Zhang, Y. H., Chen, J. H., Liu, H. J., Bao, L. F., Fan, S. J., and Tang, D.: Aircraft measurements of gaseous pollutants and particulate matter over Pearl River Delta in China, Atmos. Environ., 42, 6187-6202, 2008.

Wenig, M. O., Cede, A. M., Bucsela, E. J., Celarier, E. A., Boersma, K. F., Veefkind, J. P., Brinksma, E. J., Gleason, J. F., and Herman, J. R.: Validation of OMI tropospheric $\mathrm{NO}_{2}$ column densities using direct-sun mode Brewer measurements at NASA Goddard Space Flight Center, J. Geophys. Res., 133, D16S45, doi:10.1029/2007JD008988, 2008.

World Health Organization: WHO Air quality guidelines for particulate matter, ozone, nitrogen dioxide and sulfur dioxide Global update 2005 summary of risk assessment, Geneva, Switzerland, 2006.

Wu, F. C., Xie, P. H., Li, A., Si, F. Q., Wang, Y., and Liu, W. Q.: Correction of the impact of multi scattering on $\mathrm{NO}_{2}$ emission flux during the pollutants source measurement by mobile differential optical absorption spectroscopy, Acta Optica Sinica, 31, 1101003-1-1101003-6, doi:10.3788/AOS201131.1101003, 2011.
Xu, J., Xie, P. H., Si, F. Q., Dou, K., Li, A., Liu, Y., and Liu, W. Q.: Retrieval of tropospheric $\mathrm{NO}_{2}$ by multi axis differential optical absorption spectroscopy, Spectrosc. Spect. Anal., 30, $2464-$ 2469, 2010.

Zhang, Q., David, G. S., He, K. B., Wang, Y. X., Richter, A., Burrows, J. P., Uno, I., Jang, C. J., Chen, D., Yao, Z. L., and Lei, Y.: $\mathrm{NO}_{\mathrm{x}}$ emission trends for China, 1995-2004: the view from the ground and the view from space, J. Geophys. Res., 112, D22306, doi:10.1029/2007JD008684, 2007.

Zhang, Y. H., Hu, M., Zhong, L. J., Wiedensohler, A., Liu, S. C., Andreae, M. O., Wang, W., and Fang, S. J.: Regional integrated experiments on air quality over Pearl River Delta 2004 (PRIDEPRD2004): overview, Atmos. Environ., 42, 6157-6173, 2008a.

Zhang, Y. H., Hu, M., and Wiedensohler, A.: The special issue on PRIDE-PRD 2004 campaign, Atmos. Environ., 42, 6155-6156, 2008b.

Zheng, J. Y., Zhang, L. J., Che, W. W., Zheng, Z. Y., and Yin, S. S.: A highly resolved temporal and spatial air pollutant emission inventory for the Pearl River Delta region, China and its uncertainty assessment, Atmos. Environ., 43, 5112-5122, 2009. 